\title{
A Comprehensive Review of One-Dimensional Metal-Oxide Nanostructure Photodetectors
}

\author{
Tianyou Zhai ${ }^{1, \#, *,}$ Xiaosheng Fang ${ }^{1, \#, *}$, Meiyong Liao ${ }^{2}$, Xijin Xu ${ }^{1}$, Haibo Zeng ${ }^{1}$, Bando \\ Yoshio $^{1}$ and Dmitri Golberg ${ }^{1}$
}

1 World Premier International Center for Materials Nanoarchitectonics (MANA), National Institute for Materials Science (NIMS), Namiki 1-1, Tsukuba, Ibaraki 305-0044, Japan

2 Sensor Materials Center, National Institute for Materials Science (NIMS), Namiki 1-1, Tsukuba, Ibaraki 305-0044, Japan

\# These authors contributed equally to this work.

* Authors to whom correspondence should be addressed. E-Mails: zhai.tianyou@gmail.com or zhai.tianyou@nims.go.jp (T.Y.Z.); fang.xiaosheng@nims.go.jp (X.S.F.); Fax: +81 29-851-6280.

Received: 14 July 2009; in revised form: 5 August 2009 / Accepted: 19 August 2009 /

Published: 20 August 2009

\begin{abstract}
One-dimensional (1D) metal-oxide nanostructures are ideal systems for exploring a large number of novel phenomena at the nanoscale and investigating size and dimensionality dependence of nanostructure properties for potential applications. The construction and integration of photodetectors or optical switches based on such nanostructures with tailored geometries have rapidly advanced in recent years. Active 1D nanostructure photodetector elements can be configured either as resistors whose conductions are altered by a charge-transfer process or as field-effect transistors (FET) whose properties can be controlled by applying appropriate potentials onto the gates. Functionalizing the structure surfaces offers another avenue for expanding the sensor capabilities. This article provides a comprehensive review on the state-of-the-art research activities in the photodetector field. It mainly focuses on the metal oxide 1D nanostructures such as $\mathrm{ZnO}, \mathrm{SnO}_{2}, \mathrm{Cu}_{2} \mathrm{O}, \mathrm{Ga}_{2} \mathrm{O}_{3}, \mathrm{Fe}_{2} \mathrm{O}_{3}, \mathrm{In}_{2} \mathrm{O}_{3}, \mathrm{CdO}, \mathrm{CeO}_{2}$, and their photoresponses. The review begins with a survey of quasi 1D metal-oxide semiconductor nanostructures and the photodetector principle, then shows the recent progresses on several kinds of important metal-oxide nanostructures and their photoresponses and briefly presents some additional prospective metal-oxide 1D nanomaterials. Finally, the review is concluded with some perspectives and outlook on the future developments in this area.
\end{abstract}


Keywords: metal oxide semiconductor; one-dimensional nanostructures; sensor; photodetector; transistor

\section{Introduction}

One-dimensional (1D) nanomaterials have stimulated great interest due to their importance in basic scientific research and potential technological applications [1-3]. It is generally accepted that 1D nanostructures are ideal systems for exploring a large number of novel phenomena at the nanoscale and investigating the size and dimensionality dependence of structure properties for potential applications [4]. 1D nanomaterials are also expected to play an important role as both interconnects and functional units in fabricating electronic, optoelectronic, electrochemical, and electromechanical devices with nanoscale dimensions [5]. Among the inorganic semiconductor nanomaterials, 1D metal oxide nanostructures are the focus of current research efforts in nanotechnology since they are the most common minerals on the Earth due to their special shapes, compositions, and chemical, and physical properties. They have now been widely used in many areas, such as transparent electronics, piezoelectric transducers, ceramics, catalysis, sensors, electro-optical and electro-chromic devices [6-8]. Doubtlessly, a thorough understanding of the fundamental properties of a 1D metal oxide system is prerequisite in research and development towards practical applications.

Table 1. Fundamental physical properties of some important metal-oxide semiconductors.

\begin{tabular}{|c|c|c|c|c|}
\hline $\begin{array}{c}\text { Metal } \\
\text { oxides }\end{array}$ & Crystal structures & $\begin{array}{c}\text { Conductive } \\
\text { type }\end{array}$ & Band gap/eV & Sensing light \\
\hline $\mathrm{ZnO}$ & Hexagonal & $\mathrm{n}$ & 3.37 & $\mathrm{UV}$ \\
$\mathrm{SnO}_{2}$ & Tetragonal & $\mathrm{n}$ & 3.6 & $\mathrm{UV}$ \\
$\mathrm{Cu}_{2} \mathrm{O}$ & Cubic & $\mathrm{p}$ & 2.17 & Visible \\
$\beta-\mathrm{Ga}_{2} \mathrm{O}_{3}$ & Monoclinic & $\mathrm{n}$ & $4.2-4.9$ & $\mathrm{UV}$ \\
$\alpha-\mathrm{Fe}_{2} \mathrm{O}_{3}$ & Rhombohedral & $\mathrm{n}$ & 2.1 & Visible \\
$\mathrm{In}_{2} \mathrm{O}_{3}$ & Cubic & $\mathrm{n}$ & 3.6 (direct) & UV \\
$\mathrm{CdO}$ & Cubic & $\mathrm{n}$ & 2.5 (indirect) & (direct) \\
$\mathrm{CeO}_{2}$ & Cubic & $\mathrm{n}$ & 3.27 (indirect) & Visible/IR \\
\hline
\end{tabular}

Table 1 shows the fundamental physical properties of some important metal-oxide semiconductors, including zinc oxide $(\mathrm{ZnO})$, tin dioxide $\left(\mathrm{SnO}_{2}\right)$, copper oxide $\left(\mathrm{Cu}_{2} \mathrm{O}\right)$, Gallium oxide $\left(\beta-\mathrm{Ga}_{2} \mathrm{O}_{3}\right)$, Hematite $\left(\alpha-\mathrm{Fe}_{2} \mathrm{O}_{3}\right)$, Indium oxide $\left(\mathrm{In}_{2} \mathrm{O}_{3}\right)$, Cadmium oxide $(\mathrm{CdO})$ and Ceria $\left(\mathrm{CeO}_{2}\right)$.

Among all nanoscale devices, the photodetectors are critical for applications as binary switches in imaging techniques and light-wave communications, as well as in future memory storage and optoelectronic circuits [10,11]. With large surface-to-volume ratios and Debye length comparable to 
their small size, these 1D nanostructures have already displayed superior sensitivity to light in experimental devices. Until now, various 1D metal-oxide nanostructures have been used for the fabrication of photodetectors, and the related mechanism has been investigated over the years. This mechanism is outlined below, using $\mathrm{ZnO}$ nanowire (NW) as a model system. Essentially, all experiments carried out to date on metal-oxide nanostructures indicated that the role of oxygen vacancies is predominant for the electronic properties, similar to the bulk systems [8].

Figure 1. Photoconduction in NW photodetectors: (a) Schematic of a NW photodetector. Upon illumination with the photo-energy above Eg, electron-hole pairs are generated and holes are readily trapped at the surface. Under an applied electric field, the unpaired electrons are collected at the anode, which leads to the increase in conductivity. (b, c) Trapping and photoconduction mechanism in zinc oxide $(\mathrm{ZnO}) \mathrm{NWs}$ : the top drawing in (b) shows the schematic of the energy band diagrams of a $\mathrm{ZnO} \mathrm{NW}$ in dark, indicating band-bending and surface trap states. VB and CB are the valence and conduction bands, respectively. The bottom drawing shows oxygen molecules absorbed at the NW surface that capture the free electrons present in the n-type semiconductor forming a lowconductivity depletion layer near the surface. (c) Under light illumination, photogenerated holes migrate to the surface and become trapped, leaving behind unpaired electrons in the NW that contribute to the photocurrent. In $\mathrm{ZnO}$ NWs, the lifetime of the unpaired electrons is further increased by oxygen molecules desorption from the surface when holes neutralize the oxygen ions. Reproduced from [9].

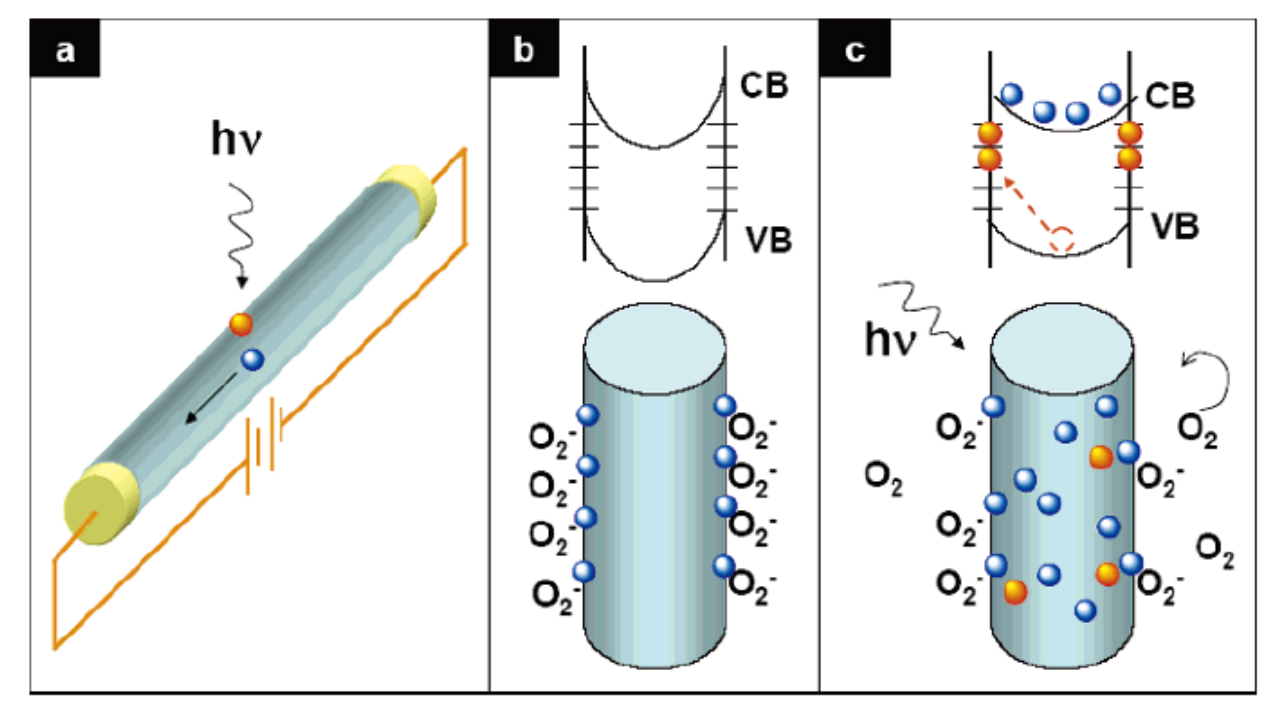

As discussed by Yang et al, Wang et al and other groups [9,12-14], in the dark, the oxygen molecules absorb on the $\mathrm{ZnO} \mathrm{NW}$ surface and capture the free electrons present in a n-type oxide semiconductor $\left[\mathrm{O}_{2}(\mathrm{~g})+e^{-} \rightarrow \mathrm{O}_{2}^{-}(\mathrm{ad})\right]$, and a low-conductivity depletion layer is formed near the surface (Figure $1 \mathrm{~b}$ ), that results in the reduction of the channel conduction. When the $\mathrm{ZnO} \mathrm{NW}$ is illuminated by a UV-light whose photon energy is above the energy gap $\left(\mathrm{E}_{\mathrm{g}}\right)$ of the $\mathrm{ZnO}$, then the electron-hole pairs are photogenerated $\left[h v \rightarrow e^{-}+h^{+}\right]$, and the holes migrate to the surface along the potential slope produced by band bending and discharge the negatively charged absorbed oxygen ions 
through surface electron-hole recombination $\left[h^{+}+O_{2}^{-}(a d) \rightarrow O_{2}(g)\right]$. Consequently, oxygen is photodesorbed from the surface. The unpaired electrons are either collected at the anode or recombine with holes generated when oxygen molecules are reabsorbed and ionized at the surface. The holetrapping mechanism through oxygen desorption in $\mathrm{ZnO}$ NWs augments the high density of trap states (usually found in NWs) due to the dangling bonds at the surface, and thus greatly increases the NW photoconductivity [9]. With respect to a traditional film photodetector, 1D metal-oxide nanostructures have several advantages. namely a large surface-to-volume ratio with the carrier and photon confinement in two dimensions, superior stability owing to high crystallinity, possible surface functionalization with target-specific receptor species, and field-effect transistor configurations that allow the use of gate potentials controlling the sensitivity and selectivity [15].

This article provides a comprehensive review of the state-of-the-art research activities that focus on several kinds of important metal-oxide nanostructures such as $\mathrm{ZnO}, \mathrm{SnO}_{2}, \mathrm{Ga}_{2} \mathrm{O}_{3}, \mathrm{Cu}_{2} \mathrm{O}, \mathrm{Fe}_{2} \mathrm{O}_{3}, \mathrm{In}_{2} \mathrm{O}_{3}$, $\mathrm{CdO}, \mathrm{CeO}_{2}$, and their corresponding photodetector applications, and briefly discusses some other metal-oxide semiconductors. In the end, we conclude this review with some perspectives/outlook and future research directions in this field.

\section{Different Photodetector Materials-Metal Oxides}

In this section, we highlight recent progresses with respect to several kinds of metal-oxide nanostructures, including $\mathrm{ZnO}, \mathrm{SnO}_{2}, \mathrm{Ga}_{2} \mathrm{O}_{3}, \mathrm{Fe}_{2} \mathrm{O}_{3}, \mathrm{In}_{2} \mathrm{O}_{3}, \mathrm{CdO}, \mathrm{Cu}_{2} \mathrm{O}$ and $\mathrm{CeO}_{2}$, and their photoresponses.

\subsection{ZnO-Based Photodetectors}

$\mathrm{ZnO}$ is one of the most prominent semiconductors in the metal-oxide family. It has a wide-band-gap of $3.37 \mathrm{eV}$ and a large exciton binding energy of $60 \mathrm{meV}$. This ensures efficient excitonic ultraviolet (UV) emission at room temperature. Besides, the non-central symmetry of $\mathrm{ZnO}$ in wurtzite structure, combined with its large electromechanical coupling, results in strong piezoelectric and pyroelectrical properties and implies a consequent usage in actuators, piezoelectric sensors and nanogenerators. $\mathrm{ZnO}$ is also bio-safe, biocompatible, and can be directly used for biomedical applications without coatings [4]. As for $1 \mathrm{D} \mathrm{ZnO}$ nanostructures, they play the key roles in developing nanoscience and nanotechnology, as illustrated by many articles published. It is fair to state that $\mathrm{ZnO} 1 \mathrm{D}$ nanostructures are probably the most important Metal-Oxide-Semiconductor 1D nanostructures in nowadays research. Growing interests in the synthesis of $\mathrm{ZnO}$ nanostructures are stimulated due to promising applications in nanoscale technologies and devices. $\mathrm{ZnO}$ diverse and versatile morphologies are probably wider than any other materials known to date $[16,17]$.

In this section, we will first give two examples related to "Nanowire Ultraviolet Photodetectors and Optical Switches", and "Photoswitches and Memories Assembled by Electrospinning AluminumDoped Zinc Oxide Single Nanowires", and then report the systematic investigations on photodetector applications based on $\mathrm{ZnO}$ nanostructures. In 2002, Yang and coworkers first found that the conductance of $\mathrm{ZnO} \mathrm{NW}$ had been extremely sensitive to ultraviolet light exposure [12]. The lightinduced conductivity enabled them to reversibly switch the NWs between OFF and ON states. In a typical experiment, four-terminal measurements on an individual $\mathrm{ZnO}$ structure indicated that they 
were almost insulating in the dark with a resistivity of $\sim 3.5 \mathrm{M} \Omega \mathrm{cm}^{-1}$. When the NWs were exposed to $365 \mathrm{~nm}$ UV-light, their resistivity was remarkably reduced by 4-6 orders of magnitude, as shown in Figure 2a. Furthermore, the NW photodetector exhibited strong power dependence (Figure 2b) and excellent wavelength selectivity (Figure 2c) [12].

Figure 2. (a) Current-Voltage (I-V) curves showing dark current and photocurrent of a single $\mathrm{ZnO} \mathrm{NW}$ under $365 \mathrm{~nm}$ UV-light illumination; (b) Photocurrent as a function of light intensity at $365 \mathrm{~nm}$; (c) Sensitivity of the photoresponse of a $\mathrm{ZnO} \mathrm{NW}$ to light exposure at a wavelength of $532 \mathrm{~nm}$ and $365 \mathrm{~nm}$; (d) Current-time (I-t) plot recorded with the UV illumination turned on and off repeatedly. Reproduced from [12].
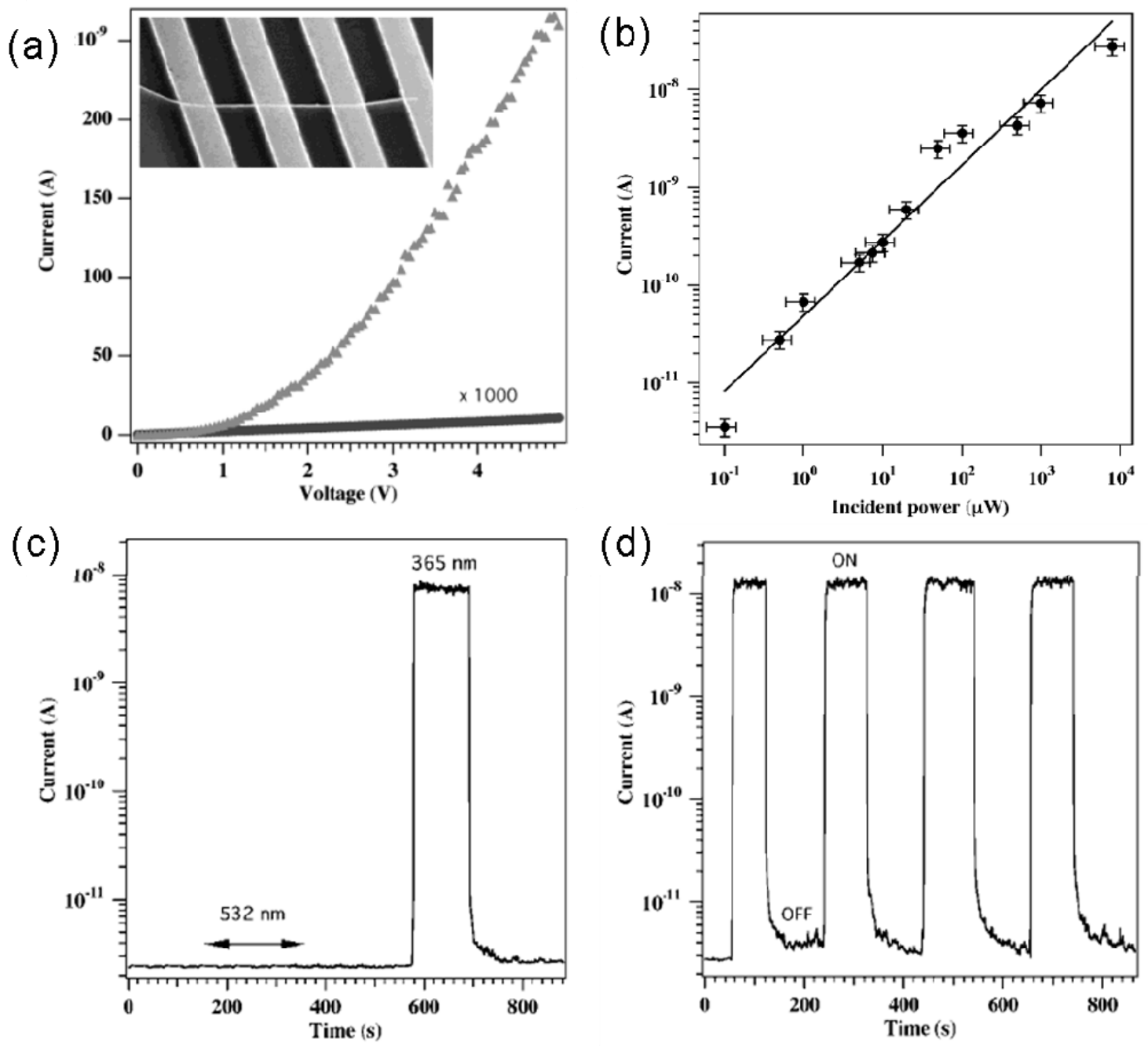

Yang et al. further evaluated the NW potential in optoelectronic switches, with the insulating state as "OFF" state in the dark, and the conductance state as "ON" when exposed to UV light. Figure $2 \mathrm{~d}$ plots the photoresponse of a $\mathrm{ZnO} \mathrm{NW}$ as a function of time while the UV-light was switched on and off. It is evident that this NW could be reversibly and rapidly switched between the low- and highconductivity states. The rise and decay times of the fastest NW switches were below the apparatus detection limit, which was roughly $1 \mathrm{~s}[5,12]$. 
After that, several researchers have dedicated themselves to improving the response of a $\mathrm{ZnO}$ 1D nanostructure photodetector, and obtained a series of remarkable achievements. He and coauthors utilized focused-ion-beam (FIB) technique to deposit Pt metal on ZnO NWs and transmission-linemethod (TLM) measurements to effectively reduce the contact resistance which was as low as $1.1 \times 10^{5} \Omega \mathrm{cm}^{2}$, and thus achieved $\mathrm{ZnO} \mathrm{NW}$-based UV photodetectors with a photoconductive gain as high as $10^{8}$ (the photoconductive gain is one of the most important physical parameters which determines the photocarrier collection efficiency) [13].

Prades and coauthors presented a set of criteria to optimize a $\mathrm{ZnO}$ NW photodetector. They enhanced its response through different fabrication strategies, such as diminishing the distance between the electrical contacts, increasing the width of the photoactive area, or improving the electrical mobility of the nanomaterials [18]. Very recently, Kim and coauthors demonstrated that drain-source $\left(\mathrm{V}_{\mathrm{ds}}\right)$ and gate-source voltages $\left(\mathrm{V}_{\mathrm{gs}}\right)$ of a $\mathrm{ZnO}$ NW FET could be optimized to increase UV photodetection sensitivity. They found that the detector was the most sensitive when it was operated with the highest on/off current ratio and at the "bottom" of the sub-threshold swing region. Their photodetector showed maximum photo- to dark- current ratio of $\sim 10^{6}$ upon UV illumination near $\mathrm{V}_{\mathrm{gs}}=-1 \mathrm{~V}$ and $\mathrm{V}_{\mathrm{ds}}=1 \mathrm{~V}$. These results could be applied to improve sensitivity of other kinds of FETbased photodetectors whose sensing mechanism is based on the change of carrier concentration [19].

Recently, several doped 1D $\mathrm{ZnO}$ nanostructures have been synthesized and investigated for enhancing and controlling $\mathrm{ZnO}$ nanostructures' mechanical, electrical and optical performances. Pan et al. reported on a photoconductor device that was sensitive to illumination with below-gap light by electrospinning a single $\mathrm{Al}$ doped-ZnO (AZO) nanowire. By using a " $\mathrm{Cu}$ bridge" as the cathode (Figure 3a), the electrospun nanowires could be uniaxially aligned over long length scales during the e-spinning process. The nanowires were then directly transferred to a $\mathrm{SiO}_{2} / \mathrm{Si}$ substrate, and calcined at $550{ }^{\circ} \mathrm{C}$ for $3 \mathrm{~h}$ to obtain well-aligned polycrystalline AZO nanowires. A typical I-V curve for a single $\mathrm{AZO}$ nanowire with different $\mathrm{Al}$ concentrations is shown in Figure 3b. Compared with the pure $\mathrm{ZnO}$ nanowires with a conductivity of $2.55 \times 10^{-5} \mathrm{~S} / \mathrm{cm}$, the Al-doped $\mathrm{ZnO}$ nanowires show a steep increase up to $9.73 \times 10^{-3} \mathrm{~S} / \mathrm{cm}(\mathrm{Al}=5 \%)$, indicating a great enhancement in conductivity. Alumina acts as a cationic dopant in the $\mathrm{ZnO}$ lattice, that is, the trivalent $\mathrm{Al}^{3+}$ ion occupies the divalent $\mathrm{Zn}^{2+}$ site $\left(A l_{\mathrm{Zn}}^{\bullet}\right)$ allowing electrons to move to the conduction band easily.

Figure $3 \mathrm{c}$ shows the I-V curves measured in dark and under illumination for comparison. As the device was illuminated by a white-light source with $\sim 400-800 \mathrm{~nm}$, the conductance of an individual AZO (Al 1.0 at\%) nanowire increased significantly from $3.36 \times 10^{-4} \mathrm{~S} / \mathrm{cm}$ to $6.67 \times 10^{-3} \mathrm{~S} / \mathrm{cm}$, which is about 20 times of that measured in darkness. The authors suggest that the notable photoresponse of the AZO nanowires may be attributed to photo-excitation of electrons from the defect levels introduced by Al doping. As light with energy below the bandgap is introduced, the electrons captured at the detect states, such as $A l_{Z n}^{\circ}, V_{Z n}^{\prime \prime}$, as well as an impurity band of ca. $80 \mathrm{meV}$ binding energy below the effective band edge of $\mathrm{ZnO}$, are photo-excited to the conduction band, as illustrated in Figure $3 \mathrm{~d}$. 
Figure 3. (a) Schematic illustration of the setup used for electrospinning nanowires as uniaxially aligned arrays; (b) The measured current-voltage (I-V) curves of undoped and Al-doped samples; (c) Photoresponse of the Al-doped $\mathrm{ZnO}$ nanowires (1 at\% $\mathrm{Al}$ ) to below-gap illumination (Au electrodes); (d) Schematic energy band diagram of the photoswitches. Reproduced from [20].
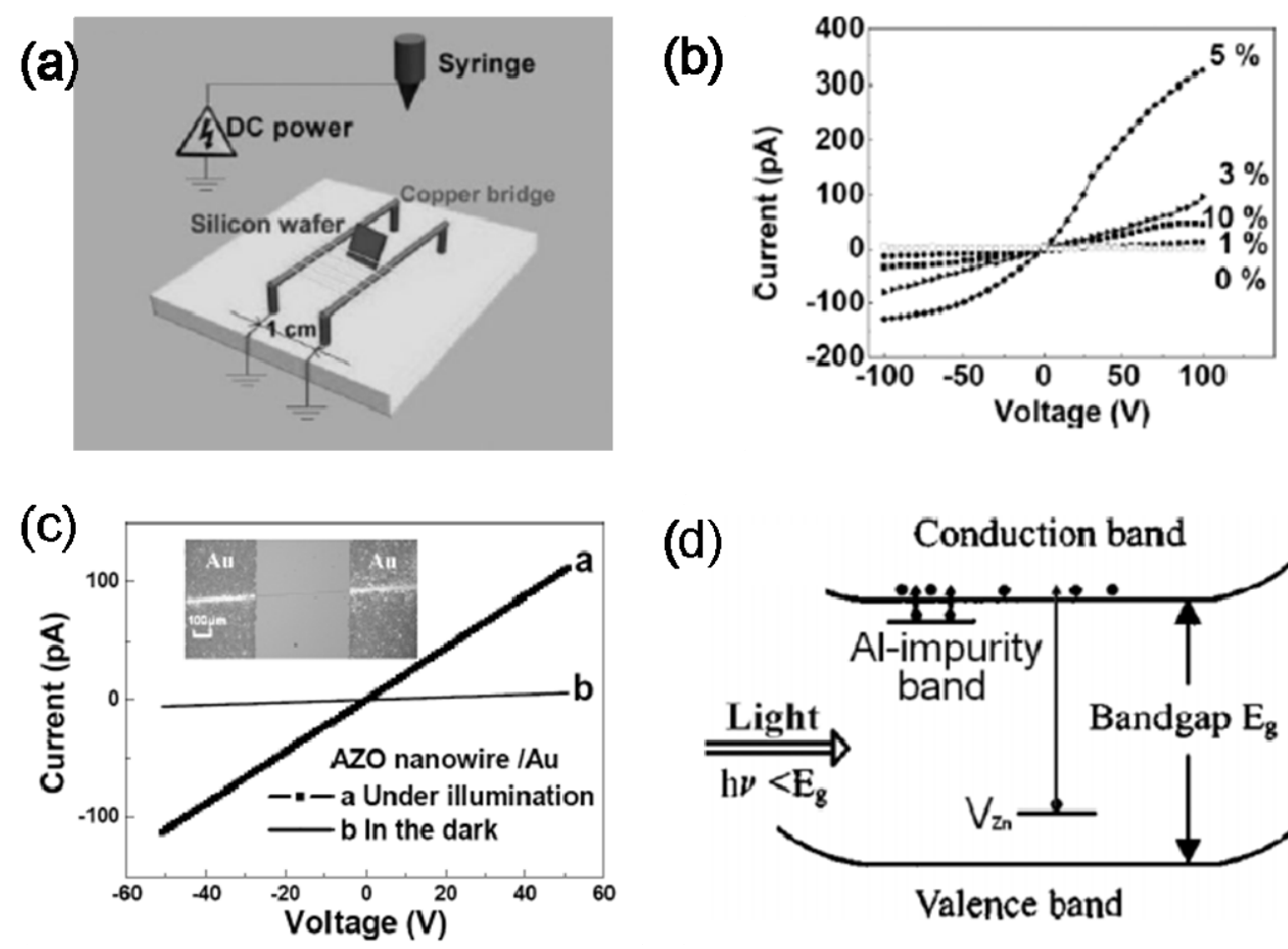

(d)

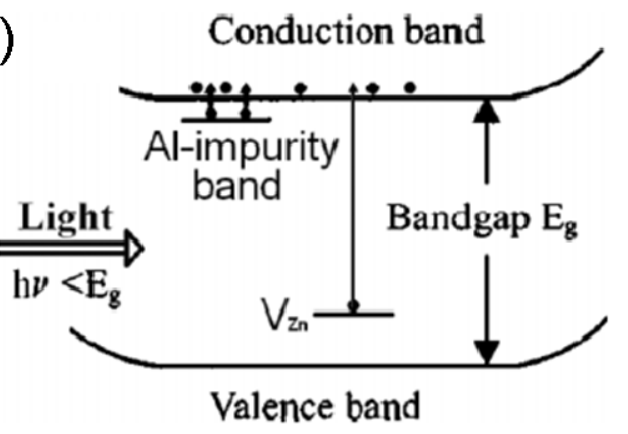

The increase in carrier density thus greatly enhances the conductivity of the AZO nanowire. In contrast, an extremely weak photoresponse of undoped $\mathrm{ZnO}$ nanowires was observed, with only a small current rise of about $6.4 \%$ [20]. Very recently, Xie et al. have found a negative photoconductivity of Co-doped $\mathrm{ZnO}$ nanobelts. The decrease of photoconductivity from 1.3 to $0.25 \mu \mathrm{A}$ in ambient air or water vapor atmosphere is observed when the Co-doped $\mathrm{ZnO}$ nanobelts are irradiated with $630 \mathrm{~nm}$ light. The authors think that this kind of negative photoconductivity is attributed to the photodesorption of water molecules from nanobelts' surface [28]. Meanwhile, Kouklin et al. reported the fabrication of $\mathrm{Cu}$-doped $\mathrm{ZnO}$ nanowires for efficient and multispectral photodetection applications. The use of $\mathrm{Cu}$ is shown to dramatically enhance the photosensitivity levels of the nanowires to both UV and visible light as a result of avalanche photomultiplication [38].

It should be stated that within last few years, tremendous progress has already been made in photodetector applications of $\mathrm{ZnO} 1 \mathrm{D}$ nanostructures. For instance, we realized that there have been more than 50 research papers published solely related to $\mathrm{ZnO} 1 \mathrm{D}$ nanostructure photodetector characteristics. Here, we tabulate the representative results on photodetector properties of $\mathrm{ZnO}$ nanostructures reported so far, along with a brief description of the corresponding device continuations, detection wavelength, and photodetector performance (Table 2). 
Table 2. ZnO-based photodetectors.*

\begin{tabular}{|c|c|c|c|c|c|c|c|c|c|}
\hline Nanostructures & Devices & Light of detection & Bias & $\begin{array}{c}\text { Dark current } \\
\text { Or conductance }\end{array}$ & $\begin{array}{c}\text { Photocurrent } \\
\text { Or conductance }\end{array}$ & $\begin{array}{l}\text { Photocurrent and } \\
\text { Dark current ratio }\end{array}$ & Rise time & Decay time & Ref. \\
\hline NW & Resistor & $390 \mathrm{~nm} ; 6.3-40 \mathrm{~mW} / \mathrm{cm}^{2}$ & 5 & $1-10 \mathrm{nA}$ & $100 \mu \mathrm{A}$ & $10^{2}-10^{5}$ & - & - & [9] \\
\hline NW & Resistor & $365 \mathrm{~nm} ; 0.3 \mathrm{~mW} / \mathrm{cm}^{2}$ & $0-5$ & $\sim 1 \mathrm{pA}$ & $\sim 250 \mathrm{nA}$ & $10^{4}-10^{6}$ & $<1 \mathrm{~s}$ & $<1 \mathrm{~s}$ & {$[12]$} \\
\hline NW & Resistor & $325 \mathrm{~nm}$ & 0.5 & $\sim 0.05 \mu \mathrm{A}$ & $\sim 0.4 \mu \mathrm{A}$ & - & - & - & {$[13]$} \\
\hline NW & Resistor & $340 \mathrm{~nm}$ & 1 & - & $20 \mathrm{nA}$ & & $170 \mathrm{~s}$ & $300 \mathrm{~s}$ & {$[18]$} \\
\hline NW & FET & $365 \mathrm{~nm} ; 0.47 \mathrm{~mW} / \mathrm{cm}^{2}$ & - & - & - & $10^{2}-10^{6}$ & - & - & [19] \\
\hline Al-ZnO NW & Resistor & $400-800 \mathrm{~nm}$ & - & $3.36 \times 10^{-4} \mathrm{~S} / \mathrm{cm}$ & $6.67 \times 10^{-4} \mathrm{~S} / \mathrm{cm}$ & - & - & - & {$[20]$} \\
\hline NW & Resistor & $\begin{array}{c}350 \mathrm{~nm} ; 50 \mathrm{nW}-48 \\
\mathrm{~mW} / \mathrm{cm}^{2}\end{array}$ & 5 & - & $\begin{array}{c}40 \mu \mathrm{A} \\
\text { for } 50 \mathrm{nW} / \mathrm{cm}^{2} \\
\end{array}$ & $10-10^{5}$ & $0.7 \mathrm{~s}$ & $1.4 \mathrm{~s}$ & {$[21]$} \\
\hline MT & Resistor & $\begin{array}{c}365 \mathrm{~nm} ; \\
21700 \mu \mathrm{W} / \mathrm{cm}^{2}\end{array}$ & 5 & $1.5 \mu \mathrm{A}$ & $\begin{array}{l}0.085 \mathrm{~mA}\left(\mathrm{O}_{2}\right) \\
0.135 \mathrm{~mA} \text { (air) } \\
0.209 \mathrm{~mA}\left(\mathrm{~N}_{2}\right) \\
0.201 \mathrm{~mA}(\mathrm{Ar})\end{array}$ & - & $\begin{array}{c}2.9 \mathrm{~s} \\
5.9 \mathrm{~s} \\
28.4 \mathrm{~s} \\
45.8 \mathrm{~s} \\
\end{array}$ & $\begin{array}{c}100 \mathrm{~s} \\
638 \mathrm{~s} \\
- \\
-\end{array}$ & {$[22]$} \\
\hline NW & Resistor & $633 \mathrm{~nm} ; 0.2 \mathrm{~W} / \mathrm{cm}^{2}$ & 2 & $13.1 \mathrm{nS}$ & $73.4 \mathrm{nS}$ & - & - & - & {$[23]$} \\
\hline ST ZnO NW & Resistor & $365 \mathrm{~nm} ; 30 \mu \mathrm{W} / \mathrm{cm}^{2}$ & 1 & $0.04 \mathrm{nA}$ & $60 \mathrm{nA}$ & 1500 & $0.6 \mathrm{~s}$ & $6 s$ & [24] \\
\hline $\begin{array}{c}\text { Nanoneedle } \\
\text { array }\end{array}$ & Resistor & $365 \mathrm{~nm} ; 16 \mu \mathrm{W} / \mathrm{cm}^{2}$ & 一 & $1.0 \times 10^{-4} \mathrm{~A}$ & $4.0 \times 10^{-4} \mathrm{~A}$ & - & - & - & {$[25]$} \\
\hline NW & Resistor & $300-425 \mathrm{~nm} ; 6 \mathrm{~mW} / \mathrm{cm}^{2}$ & 10 & $20 \mathrm{nA}$ & $140 \mathrm{nA}$ & - & - & - & [26] \\
\hline NW array & Resistor & $370 \mathrm{~nm}$ & 5 & $70 \mu \mathrm{A}$ & $100 \mu \mathrm{A}$ & - & $0.4 \mathrm{~ms}$ & - & {$[27]$} \\
\hline \multirow{2}{*}{ Co- $\mathrm{ZnO} \mathrm{NB}$} & \multirow{2}{*}{ Resistor } & $370 \mathrm{~nm}$ & \multirow{2}{*}{ - } & \multirow{2}{*}{$1.3 \mu \mathrm{A}$} & $110 \mu \mathrm{A}$ & \multirow{2}{*}{ - } & - & \multirow{2}{*}{ - } & \multirow{2}{*}[28]{} \\
\hline & & $630 \mathrm{~nm}$ & & & $0.25 \mu \mathrm{A}$ & & $500 \mathrm{~s}$ & & \\
\hline NR & Resistor & $366 \mathrm{~nm} ; 0.1 \mathrm{~W} / \mathrm{cm}^{2}$ & 1 & $1200-4000 \mathrm{M} \Omega$ & $20-500 \mathrm{M} \Omega$ & - & - & - & [29] \\
\hline NW & Resistor & $325 \mathrm{~nm} ; 10 \mathrm{~mW} / \mathrm{cm}^{2}$ & 0.5 & - & - & - & - & - & [30] \\
\hline
\end{tabular}


Table 2. Cont.

\begin{tabular}{|c|c|c|c|c|c|c|c|c|c|}
\hline Nanostructures & Devices & Light of detection & Bias & $\begin{array}{c}\text { Dark current } \\
\text { Or conductance } \\
\end{array}$ & $\begin{array}{c}\text { Photocurrent } \\
\text { Or conductance } \\
\end{array}$ & $\begin{array}{l}\text { Photocurrent and } \\
\text { Dark current ratio }\end{array}$ & Rise time & Decay time & Ref. \\
\hline NW & Resistor & $254 \mathrm{~nm} ; 7 \mathrm{~W}$ & - & $0.08 \mu \mathrm{S}$ & $2 \mu \mathrm{S}$ & $\begin{array}{c}5.8 \text { (Vacuum) } \\
66 \text { (air) }\end{array}$ & $\begin{array}{l}16 \mathrm{~s}(\mathrm{~V}) \\
66 \mathrm{~s} \text { (air) }\end{array}$ & $\begin{array}{l}188 \mathrm{~s}(\mathrm{~V}) \\
115 \mathrm{~s} \text { (air) }\end{array}$ & [31] \\
\hline $\begin{array}{c}\mathrm{ZnO} \mathrm{NB} \\
\text { PPAN-ZnO NB }\end{array}$ & Resistor & $365 \mathrm{~nm} ; 100 \mathrm{~W}$ & - & - & - & $\begin{array}{r}112 \% \\
9000 \% \\
\end{array}$ & - & - & [32] \\
\hline NW & Resistor & $\begin{array}{l}254 \mathrm{~nm}\left(0.1 \mathrm{~W} / \mathrm{cm}^{2}\right) \\
366 \mathrm{~nm}\left(0.1 \mathrm{~W} / \mathrm{cm}^{2}\right)\end{array}$ & 0.25 & $100 \mathrm{nA}$ & $\begin{array}{l}580 \mathrm{nA}(254 \mathrm{~nm}) \\
700 \mathrm{nA}(366 \mathrm{~nm})\end{array}$ & - & - & $\begin{array}{l}\text { Tens of } \\
\text { Seconds }\end{array}$ & [33] \\
\hline NW array & Resistor & $365 \mathrm{~nm} ; 0.3 \mathrm{~mW} / \mathrm{cm}^{2}$ & 5 & $1.35 \times 10^{-5} \mathrm{~A}$ & $2.0 \times 10^{-7} \mathrm{~A}$ & 150 & - & - & [34] \\
\hline NW array & Resistor & $365 \mathrm{~nm} ; 25 \mu \mathrm{W}$ & 20 & $0.15 \mu \mathrm{A}$ & $1.8 \mu \mathrm{A}$ & - & - & - & [35] \\
\hline NW arrays & Resistor & $350 \mathrm{~nm}$ & 5 & - & - & 11,64 & - & - & [36] \\
\hline NW & Resistor & $325 \mathrm{~nm}$ & 5 & - & $0.35 \mathrm{nA}$ & - & $\begin{array}{c}43.7 \mathrm{~s}(\mathrm{~V}) \\
4.6 \mathrm{~s}\end{array}$ & - & [37] \\
\hline \multirow{2}{*}{$\mathrm{Cu}-\mathrm{ZnO} \mathrm{NW}$} & \multirow{2}{*}{ Resistor } & $365 \mathrm{~nm} ; 5 \mathrm{~mW} / \mathrm{cm}^{2}$ & \multirow{2}{*}{10} & \multirow{2}{*}{$10 \mathrm{pA}$} & $100 \mathrm{nA}$ & 7000 & \multirow{2}{*}{-} & \multirow{2}{*}{ - } & \multirow{2}{*}{ [38] } \\
\hline & & Visible; $10 \mathrm{~mW} / \mathrm{cm}^{2}$ & & & - & 5000 & & & \\
\hline $\begin{array}{c}\text { NW with CdTe } \\
\text { QD }\end{array}$ & Resistor & $450 \mathrm{~nm} ; 10 \mathrm{~mW} / \mathrm{cm}^{2}$ & 2 & $10^{9} \Omega$ & $12 \mathrm{nA}$ & - & $4.7 \mathrm{~s}$ & - & [39] \\
\hline NR & Resistor & $325 \mathrm{~nm}$ & 2 & $1 \mathrm{nA}$ & $22 \mathrm{nA}$ & - & $3.7 \mathrm{~s}$ & $63.6 \mathrm{~s}$ & [40] \\
\hline NR & FET & $254 \mathrm{~nm}$ & 0.2 & - & $2.4 \mu \mathrm{A}$ & $10^{3}$ & - & $30 \mathrm{~min}$ & [41] \\
\hline NW & Resistor & $380 \mathrm{~nm}$ & 5 & $2.5 \mathrm{nA}$ & $4.5 \mathrm{nA}$ & - & - & $17.0 \mathrm{~s}$ & [42] \\
\hline NB & FET & $350 \mathrm{~nm}$ & 6.5 & - & - & 一 & - & - & [43] \\
\hline NW & Resistor & $365 \mathrm{~nm}$ & 2 & $2 \mu \mathrm{A}$ & $15 \mu \mathrm{A}$ & - & $45 \mathrm{~s}$ & $55 \mathrm{~s}$ & [44] \\
\hline NF/NWs & Resistor & $115-400 \mathrm{~nm} ; 150 \mathrm{~W}$ & 10 & $7.38 \mathrm{nA}$ & 38.62 & - & - & - & [45] \\
\hline
\end{tabular}

* NW-nanowire; MT-microtube; ND-nanoneedle; NB-nanobelt; NR-nanorod; QD-quantum dot; NF- Nanoflasks; V-vacuum 


\section{2. $\mathrm{SnO}_{2}$-Based Photodetectors}

$\mathrm{SnO}_{2}$, as another important n-type metal-oxide semiconductor, is particularly interesting and has many important applications. Its large bandgap $\left(\mathrm{E}_{\mathrm{g}}=3.6 \mathrm{eV}\right.$ at $\left.300 \mathrm{~K}\right)$ makes it ideally working as a transparent conducting electrode for organic light emitting diodes and solar cells [46,47]. In addition, $\mathrm{SnO}_{2}$ films and nanostructures have extensively been studied and used as chemical sensors for environmental and industrial applications.

Figure 4. (a) Scanning electron microscope (SEM) image of $\mathrm{SnO}_{2} \mathrm{NWs}$; (b) Gatedependent I-V curves of a single $\mathrm{SnO}_{2} \mathrm{NW}$ device; (c) I-t curve recorded with the UV illumination turned on and off repeatedly; (d) I-V curves taken with and without UV illumination. Reproduced from [46].

(a)
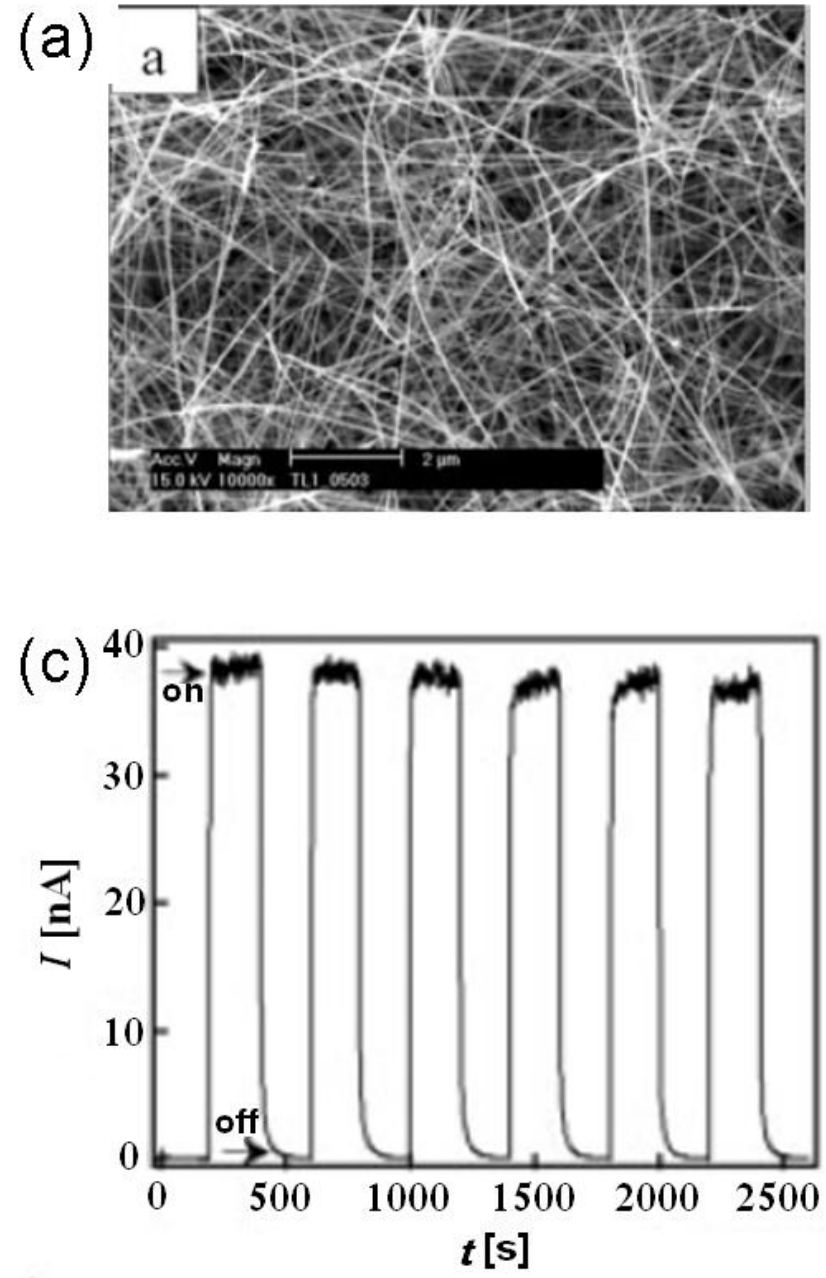

(b)
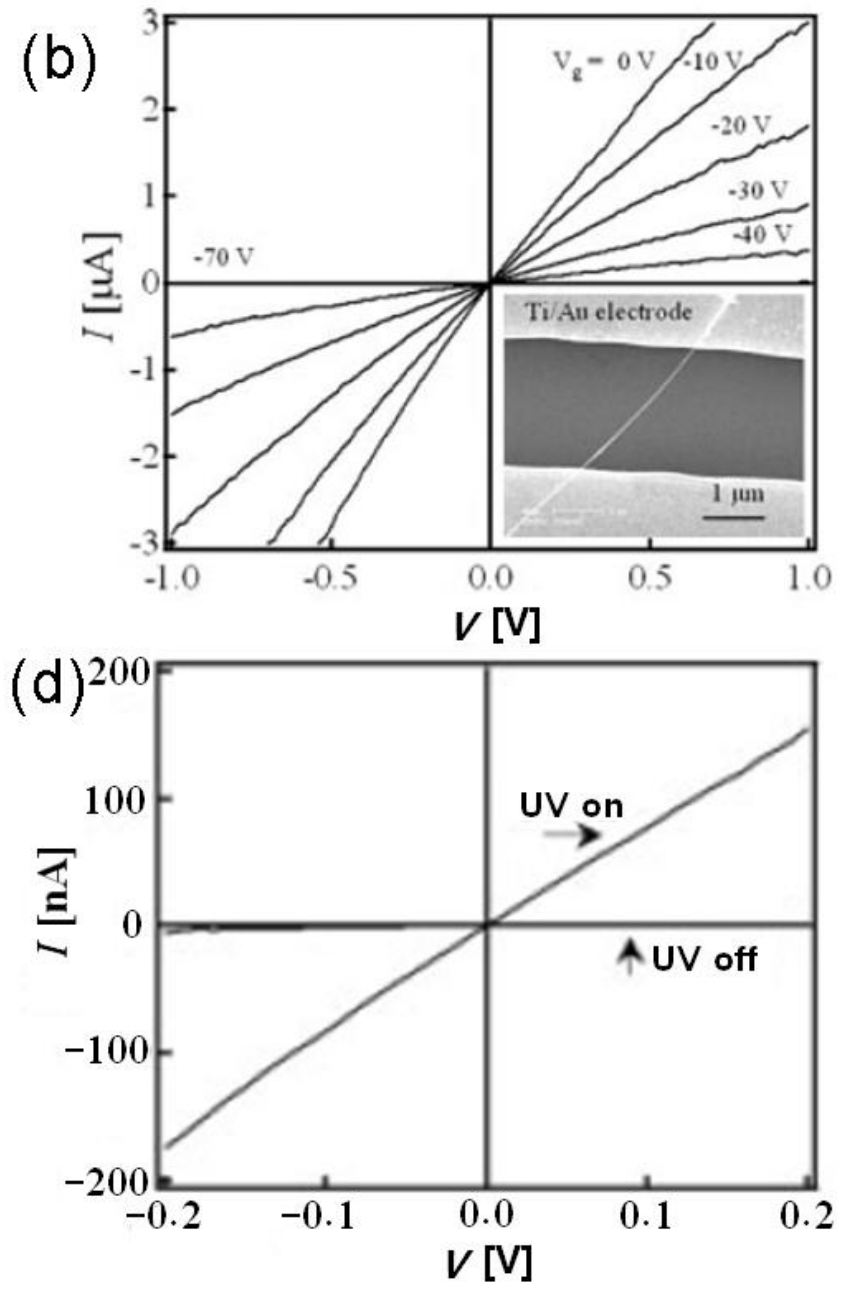

Zhou et al. reported the preparation of $\mathrm{SnO}_{2} \mathrm{NWs}$ using a laser-ablation technique. The NW diameters can be precisely controlled by using mono-dispersed gold clusters as the catalyst. Most of the NWs have diameters around $20 \mathrm{~nm}$ and lengths of the order of $10 \mu \mathrm{m}$, as illustrated in Figure 4a. Field-effect transistors were made based on these $\mathrm{SnO}_{2} \mathrm{NWs}$, and n-type transistor characteristics were recorded with threshold voltages of $50 \mathrm{~V}$ and on/off ratios of $10^{3}$ at room temperature. The authors also investigated the photoresponse properties of a $\mathrm{SnO}_{2} \mathrm{NW}$ transistor. As shown in Figure 4c, the 
current increased dramatically and stabilized a high-conductivity "on" state ( 760 nS) upon UV exposure; whereas it decreased quickly and ended up at a low-conductivity "off" state $(\sim 0.66 \mathrm{nS})$ after the UV light was blocked, leading to an on/off ratio as high as $10^{3}$. The response time of this device was less than $0.1 \mathrm{~s}$ [46]. To date, there have been only a few reports that deal with photodetector properties of $1 \mathrm{D} \mathrm{SnO}_{2}$ nanostructures, as shown in Table 3.

\section{3. $\mathrm{Cu}_{2} \mathrm{O}$-based photodetectors}

Copper oxide $\left(\mathrm{Cu}_{2} \mathrm{O}\right)$ is one of the first known p-type direct band gap semiconductors. It has the advantages of nontoxicity, low cost, availability, high absorption coefficients at $2.17 \mathrm{eV}$, and energy conversion efficiencies [49]. Its outstanding excitonic properties including a large exciton binding energy $(\sim 150 \mathrm{meV})$ have been the target of the most of research efforts during the past decades. Due to their unique physical and chemical properties, $\mathrm{Cu}_{2} \mathrm{O}$ materials have found prominent applications in field-effect transistors, photovoltaic devices, sensors, and photo-electrodes in high-efficiency photoelectrochemical cells $[48,50]$.

Figure 5. ( $a, b)$ Scanning electron microscopy (SEM) image, transmission electron microscopy (TEM) image and selected-area electron diffraction (SAED) pattern of $\mathrm{Cu}_{2} \mathrm{O}$ NWs; (c) I-V curves show dark current and photocurrent of a single $\mathrm{Cu}_{2} \mathrm{O}$ NW under $488 \mathrm{~nm}$ laser illumination; (d) I-t curves recorded with the $488 \mathrm{~nm}$ laser illumination turned on and off repeatedly. Reproduced from [48].

(a)
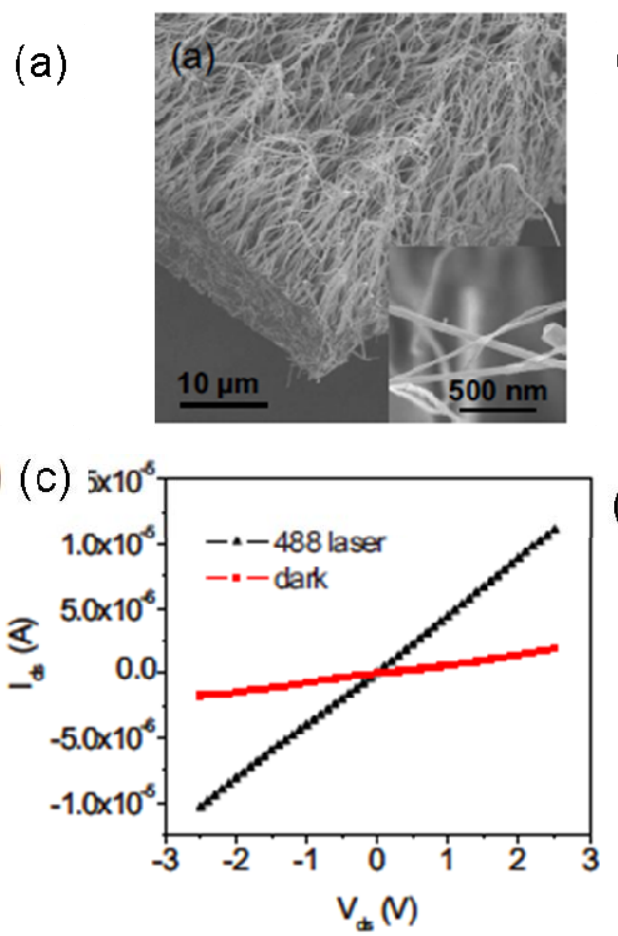

(b)

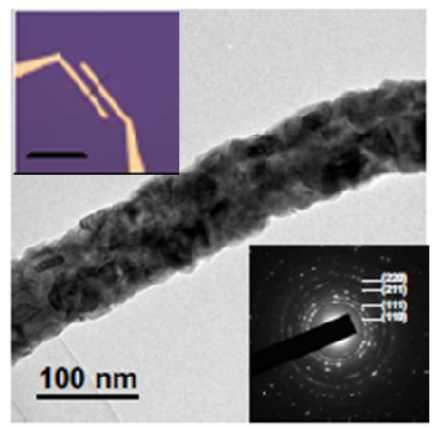

(d)

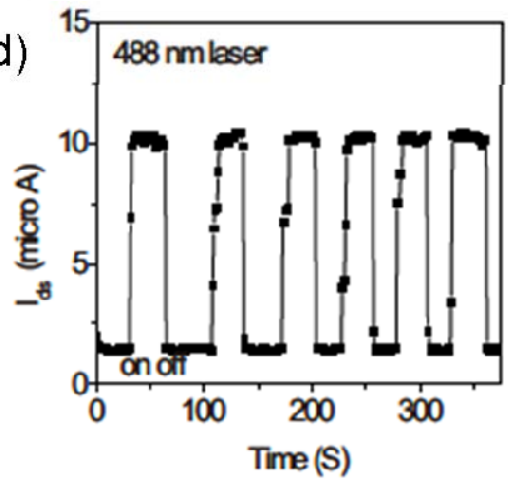

$\mathrm{Yu}$ et al. reported that $\mathrm{Cu}_{2} \mathrm{O}$ NWs could be conveniently synthesized by reduction of $\mathrm{CuO} N W s$ in hydrogen gas. The SEM image shows that the prepared aligned $\mathrm{Cu}_{2} \mathrm{O} \mathrm{NWs}$ on the substrate are $\sim 20-30 \mu \mathrm{m}$ in length and $\sim 50-100 \mathrm{~nm}$ in diameter. A typical TEM image of the $\mathrm{Cu}_{2} \mathrm{O}$ NWs is shown in Figure $5 \mathrm{~b}$. A selected area diffraction pattern of the NW reveals that it is polycrystalline. Figure $5 \mathrm{c}$ 
shows I-V characteristics of the $\mathrm{Cu}_{2} \mathrm{O} \mathrm{NW}$, measured in dark room and under blue light (488 $\mathrm{nm}$ ) laser illumination. As known, photogenerated carriers could significantly increase the conductivity when semiconductor materials are illuminated by high energy photons. Meanwhile, the large surface to volume ratio of semiconductor NWs is able to further enhance the sensitivity of the NW device to light and even possibly lead to the realization of single photoconductivity. Thus the conductance of NW increased from 0.7 to $4.3 \mu \mathrm{S}$ under the illumination. Time-resolved measurements of the photoresponse to a $488 \mathrm{~nm}$ light were conducted and the results are shown in Figure 5d. The "on" current and "off" current for each of six cycles remains the same within the noise envelope, indicating the reversibility and stability of the $\mathrm{Cu}_{2} \mathrm{O}$ NWs optical switches. The photoconductivity response time is less than three seconds. These results show that the $\mathrm{Cu}_{2} \mathrm{O}$ NW devices have a fast photoresponse to blue illumination in air and at room temperature [48].

\section{4. $\mathrm{Ga}_{2} \mathrm{O}_{3}$-based photodetectors}

Monoclinic gallium oxide $\left(\beta-\mathrm{Ga}_{2} \mathrm{O}_{3}\right)$ is a promising oxide semiconductor with a wide direct hand gap of $4.9 \mathrm{eV}$ [52,53]. It is chemically and thermally stable and has been widely used as an insulating oxide layer in gallium-based electrical devices. $\beta-\mathrm{Ga}_{2} \mathrm{O}_{3}$ is an n-type semiconductor at elevated temperatures and its semiconductivity is governed by an oxygen deficiency of the crystal lattice [54]. With its surprising bulk properties, such as conduction and luminescence, this material can be applied for high temperature gas sensing, solar cells, flat-panel displays and optical limiters for ultraviolet irradiation [55].

Figure 6. (a, b) I-V curves of a detector (a) without and (b) under $254 \mathrm{~nm}$ light illumination. Insets of Figure 5a are typical SEM images of $\beta-\mathrm{Ga}_{2} \mathrm{O}_{3} \mathrm{NWs}$ and the device; (d) I-t curves recorded with the $254 \mathrm{~nm}$ light illumination turned on and off repeatedly; (e) Enlarged rise and decay edges for the first "ON" and "OFF", respectively. Reproduced from [51].
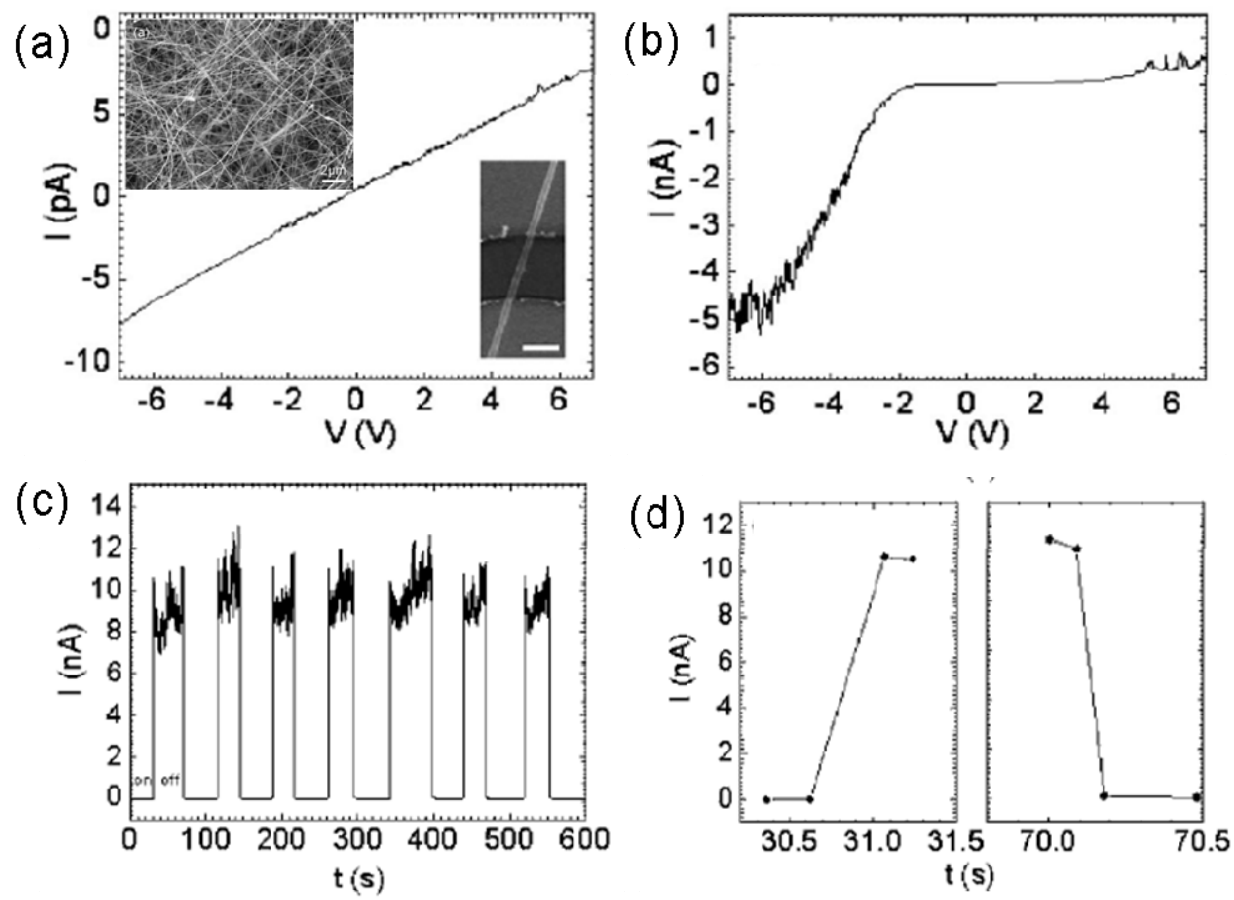
Recently, an individual $\beta-\mathrm{Ga}_{2} \mathrm{O}_{3} \mathrm{NW}$ as a solar-blind photodetector was investigated by Wang and coworkers. The SEM image depicts the general morphology of $\beta-\mathrm{Ga}_{2} \mathrm{O}_{3} \mathrm{NWs}$. They have diameters of several tens of nanometers and length of a few tens of micrometers. I-V curves of the photodetector device without and under $254 \mathrm{~nm}$ light illumination are shown in Figures 6a and 6b. As the device is exposed to illumination by an ultraviolet lamp, its conductance greatly increases. Due to the poor ohmic contacts between the electrodes and the NWs, the I-V curve of the device under illumination is asymmetric and nonlinear. Figure $6 \mathrm{~d}$ shows the real-time response of the detectors to $254 \mathrm{~nm}$ light by ON/OFF switching at a bias of $-8 \mathrm{~V}$. It can be seen that the dark current is of the order of pA. Upon illumination, the current rapidly increases to several $\mathrm{nA}$, but the current fluctuations are a little larger (maybe due to the surface species absorption/desorption or appearance of defects). As the light is off, the current suddenly decreases to its original value. The detectors operated with an upper limit of the response time of $0.22 \mathrm{~s}$, an upper limit of the recovery time of $0.09 \mathrm{~s}$, and a sensitivity of $\sim 1000$. These results demonstrate that $\beta-\mathrm{Ga}_{2} \mathrm{O}_{3} \mathrm{NWs}$ are promising materials for realizing solar-blind photodetectors [51].

\section{5. $\mathrm{Fe}_{2} \mathrm{O}_{3}$-based photodetectors}

Hematite $\left(\alpha-\mathrm{Fe}_{2} \mathrm{O}_{3}\right)$ is a stable $n$-type semiconductor with unique magnetic properties and thermal stability. Due to its narrow band gap of $2.1 \mathrm{eV}, \alpha-\mathrm{Fe}_{2} \mathrm{O}_{3} \mathrm{NWs}$ were applied in water splitting and solar cells [56].

Figure 7. (a) SEM image of $\mathrm{Fe}_{2} \mathrm{O}_{3}$ nanobridge photodetectors; (b) On/off ratio as a function of time under light illumination at 400, 490, 600, 700, and $800 \mathrm{~nm}$; (c) Response time of the $\alpha-\mathrm{Fe}_{2} \mathrm{O}_{3}$ nanobridge to pulsed light illumination $(490 \mathrm{~nm}$ ); (d) On/off ratio as a function of time under light illumination at $420 \mathrm{~nm}$ in air, vacuum and Ar. Reproduced from [56].

(a)
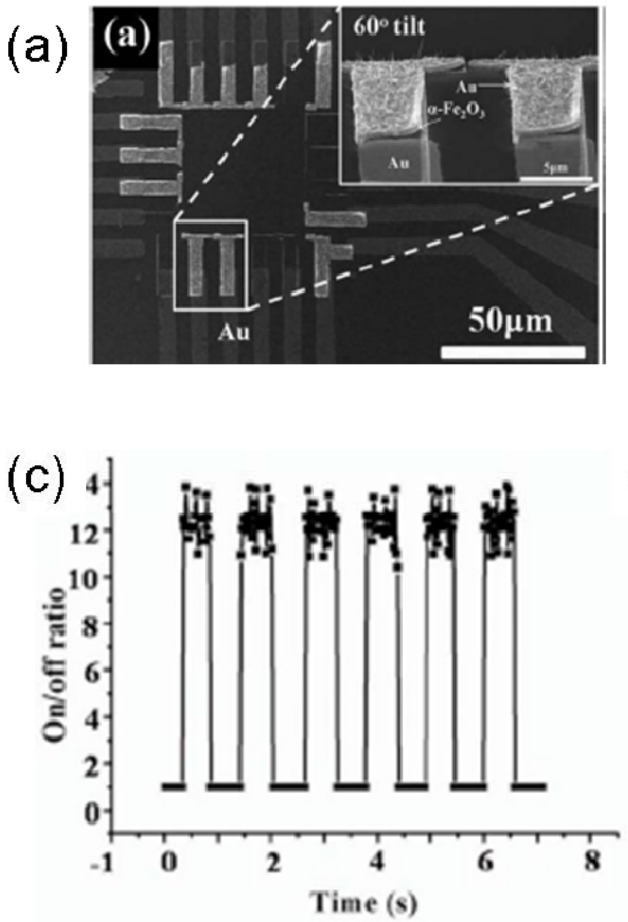
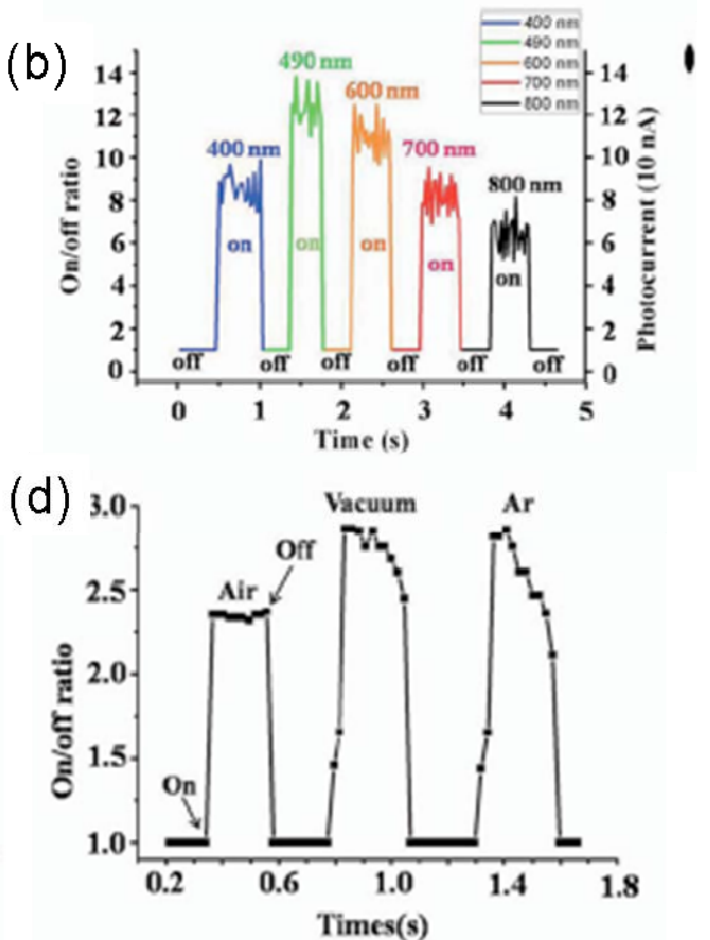
$\mathrm{Li}$ et al. for the first time reported a visible light photodetector made of an individual $\alpha-\mathrm{Fe}_{2} \mathrm{O}_{3} \mathrm{NW}$. The authors introduced a simple thermal oxidation process to form an individual $\alpha-\mathrm{Fe}_{2} \mathrm{O}_{3}$ nanobridge (NB) photodetector with a diameter of $8 \mathrm{~nm}$ between the electrodes on a $\mathrm{Si}_{3} \mathrm{~N}_{4} / \mathrm{Si}$ substrate. From the SEM (Figure 7a) and TEM images, it is understood that the NWs had been grown laterally from one side of the Fe film to another, which acted as a NB to connect the two patterns. The diameter and the length of an individual NB were $\sim 8 \mathrm{~nm}$ and $\sim 240 \mathrm{~nm}$, respectively. HRTEM and SAED results demonstrated that the NWs are crystallized in a rhombohedral structure with the growth direction along the [110]. The photocurrent properties of an individual $\alpha-\mathrm{Fe}_{2} \mathrm{O}_{3} \mathrm{NB}$ device were then investigated in detail. The photocurrent can be enhanced by illumination at 400-800 nm (visible light). The maximum photocurrent was $\sim 123 \mathrm{nA}$ at $\sim 490 \mathrm{~nm}$. As shown in Figure $7 \mathrm{~b}$, the on/off ratios were $\sim 12$ for $490 \mathrm{~nm}$ and 11 for $600 \mathrm{~nm}$, and the response time for the visible light was less than $20 \mathrm{~ms}$. The gain of the $\alpha-\mathrm{Fe}_{2} \mathrm{O}_{3} \mathrm{NB}$ device was calculated to be $2.9 \times 10^{7}$. The authors also investigated the response of the on/off ratio with or without illumination in air, Ar or vacuum. The measured photocurrents and response time were both increased in oxygen-free environment (under vacuum or Ar) as shown in Figure $7 d[56]$.

\section{6. $\mathrm{In}_{2} \mathrm{O}_{3}$-Based Photodetector}

$\mathrm{In}_{2} \mathrm{O}_{3}$ is a wide-bandgap transparent semiconductor (with a direct bandgap of $\sim 3.6 \mathrm{eV}$ and an indirect bandgap of $\sim 2.5 \mathrm{eV}$ ). In its bulk form, the material has been widely used in solar cells and organic light-emitting diodes. More importantly, $\operatorname{In}_{2} \mathrm{O}_{3}$ films have been demonstrated to work as ultrasensitive toxic-gas detectors with detection levels down to $5 \mathrm{ppm}$ for $\mathrm{NO}_{2}$, due to the surface interaction and electron transfer between $\mathrm{NO}_{2}$ molecules and $\operatorname{In}_{2} \mathrm{O}_{3}$ surface. $1 \mathrm{D} \operatorname{In}_{2} \mathrm{O}_{3}$ nanostructures are expected to offer enhanced sensitivity and an improved response time due to the increased surfaceto-volume ratios. Zhou's group has conducted an excellent work on the fabrication, electronic transport and ultraviolet photodetection properties of $\mathrm{In}_{2} \mathrm{O}_{3} \mathrm{NWs}$ [57-59]. The $\mathrm{In}_{2} \mathrm{O}_{3} \mathrm{NWs}$ were synthesized using a laser ablation technique via the vapor-liquid-solid mechanism. The SEM and TEM results show that these NWs have well-controlled diameters of $10 \mathrm{~nm}$ and lengths exceeding $3 \mu \mathrm{m}$. The HRTEM image demonstrates that the NWs have single-crystalline structures grown along the [100] direction. Devices based on individual $\mathrm{In}_{2} \mathrm{O}_{3}$ NW display a substantial increase in conductance (of up to four orders of magnitude) upon exposure to UV light, as shown in Figure 8b. Figure 8d presents the time response of the device after its exposure to the $365 \mathrm{~nm}$ and $254 \mathrm{~nm}$ lights sequentially. UV light with a wavelength of $365 \mathrm{~nm}$ brought a current to $\sim 33 \mathrm{nA}$. Significantly stronger conduction (290 nA) was observed upon exposure to a $254 \mathrm{~nm}$ UV light. The differences in conductions are attributed to different excited models. The photo energy of $254 \mathrm{~nm}(4.9 \mathrm{eV})$ light is larger than the $\operatorname{In}_{2} \mathrm{O}_{3}$ direct bandgap $(3.6 \mathrm{eV})$. This sufficiently excites electrons directly from the valence band to the conduction band. In contrast, the photo energy for a $365 \mathrm{~nm}$ light is smaller than that of $\operatorname{In}_{2} \mathrm{O}_{3} \mathrm{NWs}$ but larger than the indirect energy gap of $2.5 \mathrm{eV}$. This results in the indirect transitions. Furthermore, the authors have also demonstrated that the UV light can be used as a "gas cleaner" for $\operatorname{In}_{2} \mathrm{O}_{3} \mathrm{NW}$ chemical sensors, leading to a recovery time as short as $80 \mathrm{~s}$ [57]. However, as a photodetector, the dark decay time of this $\mathrm{In}_{2} \mathrm{O}_{3}$ device operated at $254 \mathrm{~nm}$ is a little longer. 
Figure 8. (a) HRTEM image of an $\mathrm{In}_{2} \mathrm{O}_{3} \mathrm{NW}$ and SEM image of a NW device; (b) I-V curves recorded before UV light illumination and after exposure to UV light at a wavelength of $365 \mathrm{~nm}$ and $254 \mathrm{~nm}$, respectively; (c) I-t curves recorded with the $254 \mathrm{~nm}$ UV light illumination turned on and off repeatedly; (d) Photoresponse of the $\operatorname{In}_{2} \mathrm{O}_{3}$ NW to sequential UV illumination at a wavelength of $365 \mathrm{~nm}$ and $254 \mathrm{~nm}$. Reproduced from [57].

(a)

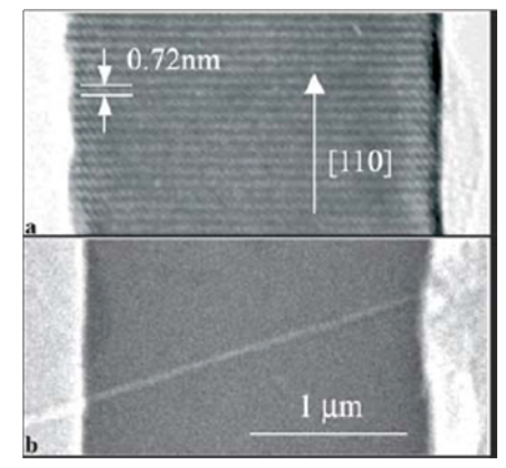

(c)

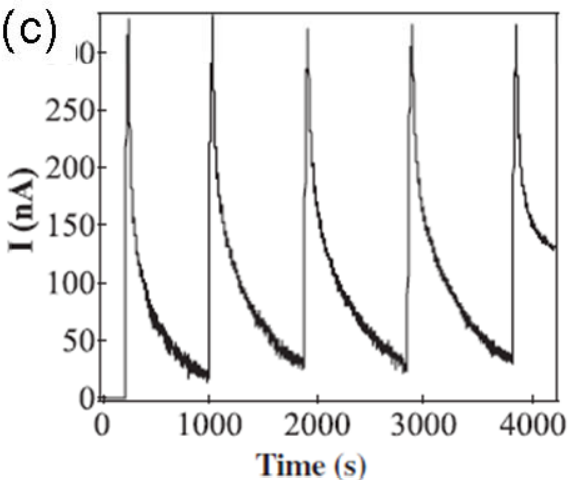

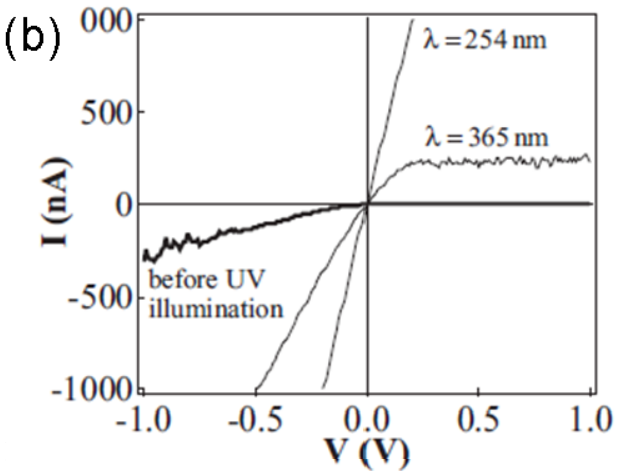

(d)

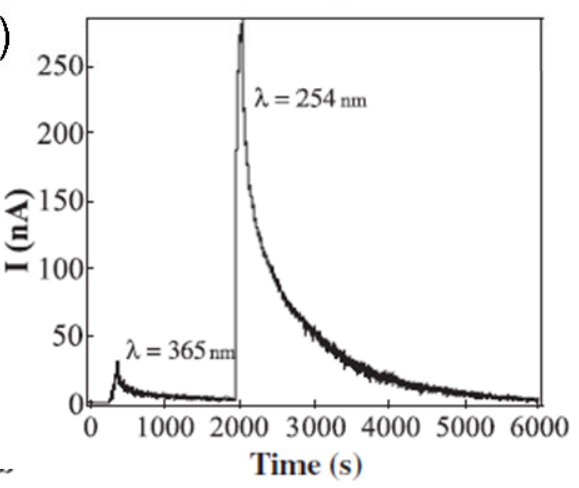

\subsection{CdO-Based Photodetectors}

Among conductive oxide (TCO) materials $\mathrm{CdO}$ shows a high promise. It exhibits a wide direct band gap of $2.27 \mathrm{eV}$ and a narrow indirect band gap of $0.55 \mathrm{eV}$. Several techniques have been used to grow $1 \mathrm{D} \mathrm{CdO}$ nanostructures, such as nanowires, nanobelts, and nanoneedles. Figure 9a shows a TEM image of a single $\mathrm{CdO}$ nanoneedle grown by VLS mechanism under a chemical vapor deposition process. The SAED pattern demonstrates that the $\mathrm{CdO}$ nanoneedles are single crystals with a cubic crystal structure grown along the [220] direction. The electrical transport and photoresponse properties were studied by fabricating electrodes onto individual nanoneedles, as illustrated in Figure 9b. Electrical properties were measured at different temperatures, revealing that the transport is dominated by thermal excitation. These $\mathrm{CdO}$ nanoneedle devices can absorb IR light via the indirect band gap mechanism rather than under the direct band gap process. The IR detection on/off ratio is $\sim 8.6$ at $1.2 \mathrm{~K}$ and the relaxation time constant is estimated to be $8.6 \mathrm{~s}$ [60]. The experiments on IR detectors were carried out at $1.2 \mathrm{~K}$ to minimize the thermal excitation. These results indicate that these IR detectors may only work at low temperatures, not at room temperature, which will restrict its practical application. 
Figure 9. (a) TEM image and SAED pattern of a CdO nanoneedle; (b) Temperaturedependent I-V curves recorded with the temperature ranging from $290 \mathrm{~K}$ to $1.2 \mathrm{~K}$; (c) I-V curves measured at $1.2 \mathrm{~K}$ with the IR light source on and off, respectively; (d) Real-time measurement of IR response of the nanoneedle device. Reproduced from [60].

(a)
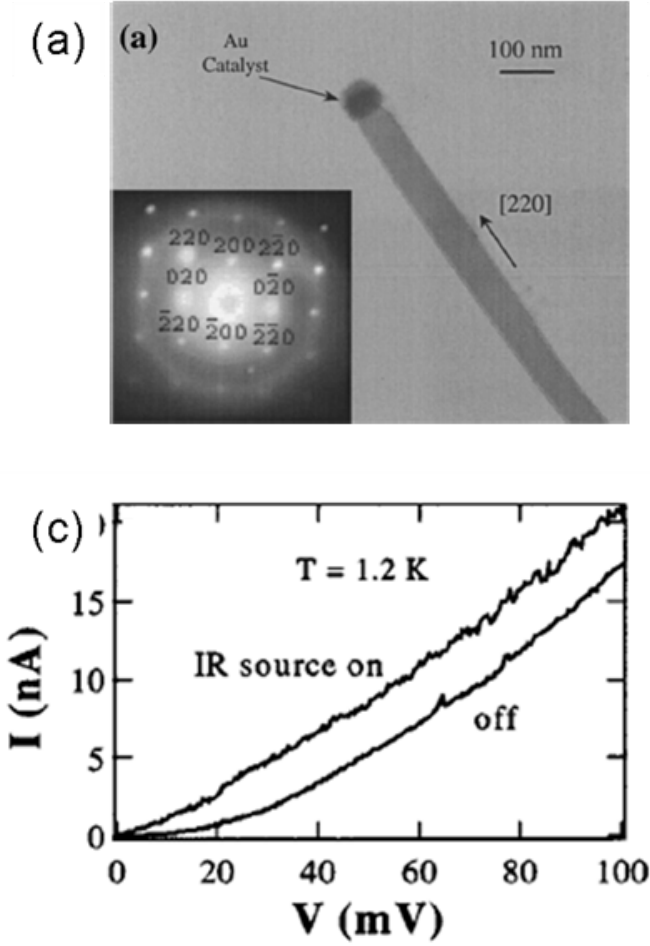

(b)
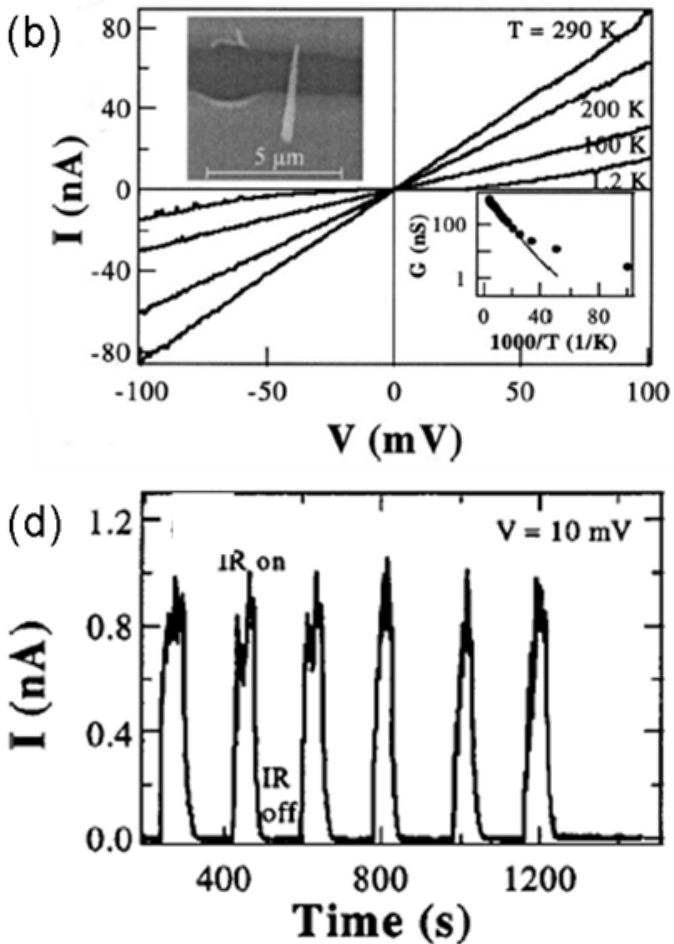

\section{8. $\mathrm{CeO}_{2}$-Based Photodetectors}

As a well-known functional rare earth material, $\mathrm{CeO}_{2}$ has widely been applied in many fields such as catalysts, gas sensors and optics due to its unique properties. It has strong absorption in the UV region and is used as a UV blocking and shielding material [62]. Wang et al. reported the fabrication of $\mathrm{CeO}_{2} \mathrm{NWs}$ via a wet chemical route. These NWs, with diameters of 20-40 nm and lengths of several micrometers, were dispersed on interdigital electrodes. As shown in Figure 10a, the dark current is $\sim 22.8 \mathrm{nA}$ in air; in contrast, upon exposure to UV illumination, the current decreases rapidly to $10 \mathrm{nA}$ and then gradually decreases to $0.25 \mathrm{nA}$ in $300 \mathrm{~s}$, which is different from the traditional photodetectors. The authors also investigated the photoresponse behavior of the device in vacuum, $\mathrm{H}_{2} \mathrm{O} / \mathrm{Ar}$ mixed gas and different dry $\mathrm{O}_{2}$ pressure conditions, as depicted in Figures 10c and 10d. As the pressure decreases (air to vacuum), the current decreases by nearly five orders of magnitude, from 17.1 to $1.6 \times 10^{-4} \mathrm{nA}$. When $\mathrm{H}_{2} \mathrm{O} / \mathrm{Ar}$ mixed gas and $\mathrm{O}_{2}$ are introduced into the chamber, the photocurrent increases rapidly. The authors suggested that this anomalous behavior, i.e., negative $\mathrm{CeO}_{2} \mathrm{NWs}$ photoconductivity in air, was due to UV-induced desorption of $\mathrm{H}_{2} \mathrm{O}$ from the nanowire's surface [61]. In regard of the photodetector application, the on-off ratio of the $\mathrm{CeO}_{2}$ device is a little lower and the response time is a little longer. 
Figure 10. (a) UV response of $\mathrm{CeO}_{2} \mathrm{NWs}$; (b) I-t curves of the device measured in air and vacuum; (c) Photocurrent response in $\mathrm{H}_{2} \mathrm{O} / \mathrm{Ar}$ mixed air; (d) $\mathrm{UV}$ response of $\mathrm{CeO}_{2} \mathrm{NWs}$ in different dry $\mathrm{O}_{2}$. Reproduced from [61].
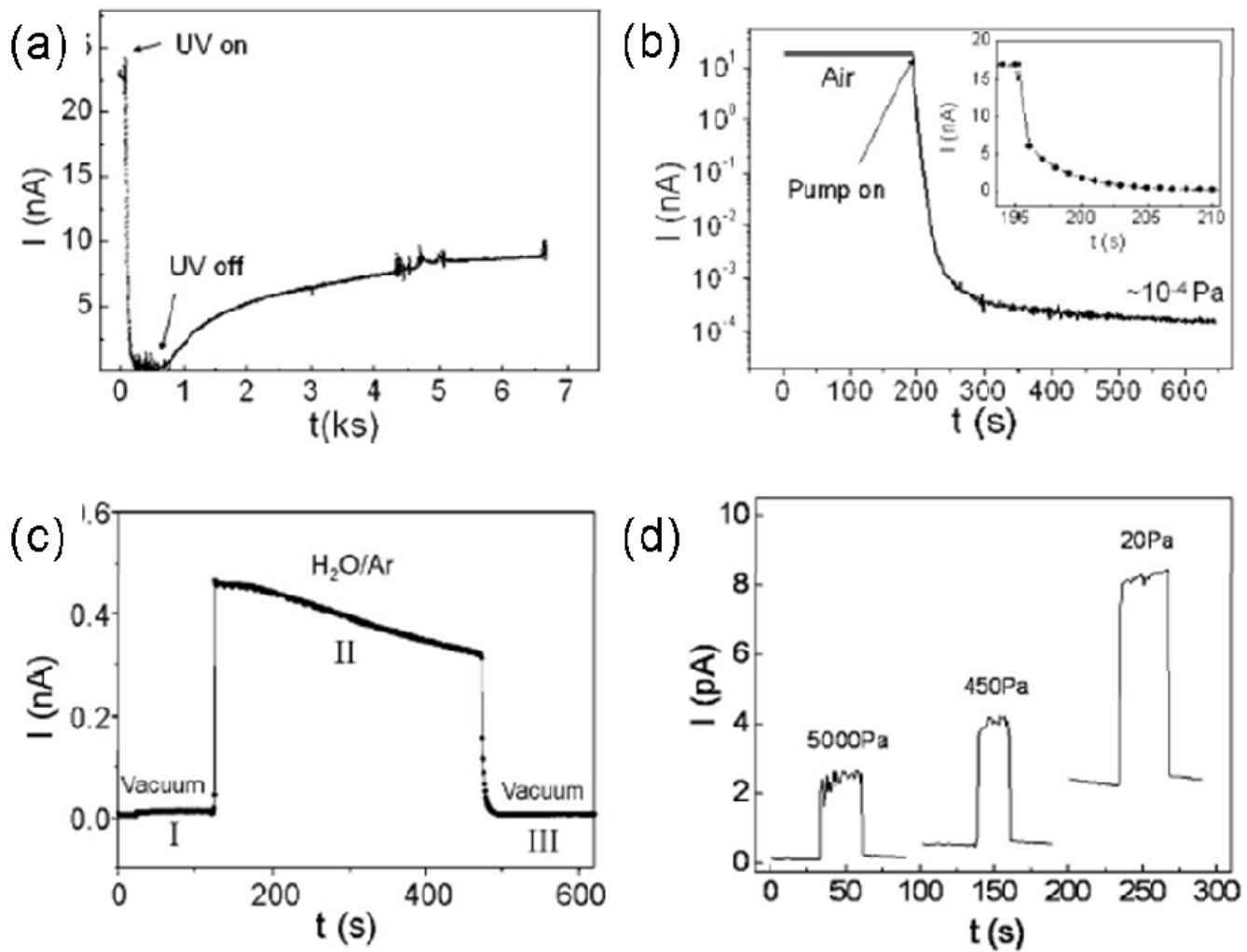

\subsection{Ternary Oxide-Based Photodetectors}

\subsection{1. $\mathrm{ZnSnO}_{3}$-based photodetectors}

Yue et al. reported the photoconducting properties of individual $\mathrm{ZnSnO}_{3} \mathrm{NWs}$ by performing transport measurements under UV and green laser illumination on/off circles [63]. For their experiments, the $\mathrm{ZnSnO}_{3} \mathrm{NWs}$ were synthesized by thermal evaporation of $\mathrm{ZnO}, \mathrm{SnO}$ and graphite mixed powders. Such NWs possessed core-shell structures. Upon exposure to UV illumination, the current of an individual $\mathrm{ZnSnO}_{3} \mathrm{NW}$ increases by about three orders of magnitude, from $0.3 \mathrm{nA}$ to $162 \mathrm{nA}$ within $20 \mathrm{~s}$. And the current increases to $6.6 \mathrm{nA}$ in $20 \mathrm{~s}$ under green laser illumination. Such behavior was ascribed to a fact that the illuminations adjusted the grain boundary barrier (that between the core and the shell) [63].

\subsection{2. $\mathrm{ZnGa}_{2} \mathrm{O}_{4}$-based photodetectors}

Zinc gallate $\left(\mathrm{ZnGa}_{2} \mathrm{O}_{4}\right)$, with a band gap of $4.4-4.7 \mathrm{eV}$, is potentially of great technological interest for the development of luminescence, vacuum electronics and multicolor emitting phosphors. The material has received a significant attention [64]. Feng et al. fabricated $\mathrm{ZnGa}_{2} \mathrm{O}_{4} \mathrm{NWs}$ via a lowpressure chemical vapor deposition method using Ga metal and $\mathrm{ZnO}$ nanopowders as the sources and investigated the electrical transport. The NWs have diameters of several tens of nanometers and lengths of a few tens of micrometers. It was found that the current across individual NW was several 
pA at a bias of $30 \mathrm{~V}$, and the current was sensitive to oxygen and temperature. These behaviors were still maintained as the $\mathrm{ZnGa}_{2} \mathrm{O}_{4} \mathrm{NWs}$ were exposed to below-band-gap irradiation. In contrast, upon exposure to a $254 \mathrm{~nm}$ UV light, the current drastically increased. With decreasing oxygen pressure or increasing temperature, the photocurrent also increased. The authors demonstrated that the surfacerelated processed (especially oxygen chemisorptions) had significant effects on the nanostructure photoelectronic properties [64].

\subsection{3 $\mathrm{RuO}_{2} / \mathrm{TiO}_{2}$ core/shell nanowire-based photodetectors}

Chou et al. reported the fabrication of $\mathrm{RuO}_{2} / \mathrm{TiO}_{2}$ core/shell NWs by reactive sputtering, and investigated photoconductive properties [65]. These core-shell NWs had a square-like cross section and lengths of several micrometers. Upon exposure to a $256 \mathrm{~nm} \mathrm{UV}$ light, the current of the $\mathrm{RuO}_{2} / \mathrm{TiO}_{2}$ core/shell structure rapidly increased, from $18.5 \mu \mathrm{A}$ to $19.4 \mu \mathrm{A}$ within $88 \mathrm{~s}$, and then slowly increased to become saturated at $20 \mu \mathrm{A}$ within $219 \mathrm{~s}$ during the first illumination. After the UV light was turned off, the current decreased from $20 \mu \mathrm{A}$ to $19.4 \mu \mathrm{A}$ within $52 \mathrm{~s}$ and then slowly recovered to the original value (under $385 \mathrm{~nm}$ illumination). The authors noted that the current decay rate was faster than the current increment rate. This was explained by a fact that water and oxygen molecules fast adsorbed on the surface via physiabsorption and chemiabsorption because of the large surface-to-volume ratio. The process resulted in a drastic drop in conductance as the UV light was turned off [65].

\section{Conclusions and Outlook}

In summary, this article provides a comprehensive review on recent advances in some important 1D metal-oxide nanostructures and their photodetector properties. Tables 2 and 3 are the up-to-date summaries of most important reports on photodetectors made of several metal-oxide nanostructures. Needless to say, due to the tremendous research efforts and the space limitations, this article is unable to cover all the exciting works reported in this field.

It is noted that photoconductors based on 1D metal-oxide nanostructures have acquired fascinating achievements just in the last 10 years. However, the ways towards their practical applications are still endless and tortuous. This should inspire more research efforts to address the challenges that remain, as noted below:

1. Nanomaterial fabrication: As known, the material is the milestone of a device. The growth kinetics and thermodynamics involved in the synthesis of metal-oxide nanostructures are extremely complex, and presume different mechanisms under different growth conditions. Although comprehensive efforts have been made towards the synthesis of high-quality metaloxide nanostructures, significant challenges still exist in their syntheses that include, but not limited to, reliable control of diameter, length, orientation, density, crystallization and hierarchical assembly. 
Table 3. Metal oxide-based photodetectors. *

\begin{tabular}{|c|c|c|c|c|c|c|c|c|c|c|}
\hline Metal oxides & Nanostructures & Devices & $\begin{array}{l}\text { Light of } \\
\text { detection }\end{array}$ & $\begin{array}{l}\text { Bias } \\
(\mathrm{V})\end{array}$ & $\begin{array}{c}\text { Dark current } \\
\text { or conductance }\end{array}$ & $\begin{array}{c}\text { Photocurrent } \\
\text { or conductance }\end{array}$ & $\begin{array}{l}\text { Photocurrent and } \\
\text { Dark current ratio }\end{array}$ & Rise time & $\begin{array}{c}\text { Decay } \\
\text { time }\end{array}$ & Ref. \\
\hline \multirow{7}{*}{$\mathrm{SnO}_{2}$} & NW & Resistor & $370 \mathrm{~nm}$ & - & $37.5 \mathrm{k} \Omega$ & $12.5 \mathrm{k} \Omega$ & - & - & - & [47] \\
\hline & NW & FET & $254 \mathrm{~nm}$ & 0.05 & $0.66 \mathrm{nS}$ & $760 \mathrm{nS}$ & $10^{3}$ & - & $<0.1 \mathrm{~s}$ & {$[46]$} \\
\hline & \multirow{2}{*}{ NB } & \multirow{2}{*}{ Resistor } & $\begin{array}{l}254 \mathrm{~nm} ; \\
10 \mathrm{~mW}\end{array}$ & \multirow{2}{*}{-5} & $0.4 \mathrm{nA}$ & $\begin{array}{c}80 \mu \mathrm{A} \text { (air) } \\
900 \mu \mathrm{A} \text { (vacuum) }\end{array}$ & $\begin{array}{c}10^{5} \text { (air) } \\
10^{6} \text { (vacuum) }\end{array}$ & - & - & \multirow{2}{*}[66]{} \\
\hline & & & $\begin{array}{c}532 \mathrm{~nm} ; \\
0.1-35.1 \mathrm{~mW}\end{array}$ & & $1.4 \mathrm{nA}$ & $57 \mathrm{nA}$ & - & $<1 \mathrm{~s}$ & $<1 \mathrm{~s}$ & \\
\hline & NW & Resistor & $\begin{array}{c}325 \mathrm{~nm} ; \\
100 \mathrm{~W} / \mathrm{m}^{2}\end{array}$ & 0.1 & $30 \mathrm{nA}$ (air) & $\begin{array}{c}210 \mathrm{nA} \text { (air) } \\
1.2 \mu \mathrm{A} \text { (Vacuum) }\end{array}$ & - & - & - & [67] \\
\hline & NW & & & - & & $235 \mathrm{nA}$ & - & - & - & \\
\hline & $\begin{array}{c}\mathrm{ZnO} \text {-functional } \\
\mathrm{SnO}_{2} \mathrm{NW} \\
\end{array}$ & Resistor & $365 \mathrm{~nm}$ & - & $200 \mathrm{nA}$ & $300 \mathrm{nA}$ & 1.50 & - & - & [68] \\
\hline $\mathrm{Cu}_{2} \mathrm{O}$ & NW & Resistor & $488 \mathrm{~nm}$ & 3 & $0.7 \mu \mathrm{S}$ & $4.3 \mu \mathrm{S}$ & $\sim 6$ & $<3 \mathrm{~s}$ & $<3 \mathrm{~s}$ & [48] \\
\hline \multirow{2}{*}{$\beta-\mathrm{Ga}_{2} \mathrm{O}_{3}$} & NW & Resistor & $254 \mathrm{~nm} ; 7 \mathrm{w}$ & 8 & $\begin{array}{c}\text { Several pA } \\
(15 \mathrm{pA})\end{array}$ & $\begin{array}{c}\text { Several nA } \\
(10 \mathrm{nA})\end{array}$ & $\sim 1000$ & $0.22 \mathrm{~s}$ & $0.09 \mathrm{~s}$ & [51] \\
\hline & NW & Resistor & $254 \mathrm{~nm}$ & 20 & $\sim 26 \mathrm{pA}$ & $\begin{array}{c}\sim 0.56-0.0095 \mathrm{nA} \\
\left(\mathrm{P}_{\mathrm{O} 2}=22-20000 \mathrm{~Pa}\right)\end{array}$ & - & - & - & {$[53]$} \\
\hline
\end{tabular}


Table 3. Cont.

\begin{tabular}{|c|c|c|c|c|c|c|c|c|c|c|}
\hline Metal oxides & Nanostructures & Devices & $\begin{array}{l}\text { Light of } \\
\text { detection }\end{array}$ & $\begin{array}{l}\text { Bias } \\
(\mathrm{V}) \\
\end{array}$ & $\begin{array}{c}\text { Dark current } \\
\text { or conductance }\end{array}$ & $\begin{array}{l}\text { Photocurrent } \\
\text { or conductance }\end{array}$ & $\begin{array}{l}\text { Photocurrent and } \\
\text { Dark current ratio }\end{array}$ & $\begin{array}{l}\text { Rise } \\
\text { time }\end{array}$ & $\begin{array}{l}\text { Decay } \\
\text { time }\end{array}$ & Ref. \\
\hline $\mathrm{CdO}$ & ND & Resistor & $950 \mathrm{~nm}$ & 0.01 & $13.3 \mathrm{nS}$ & $114.5 \mathrm{nS}$ & 8.6 & - & - & [60] \\
\hline $\mathrm{In}_{2} \mathrm{O}_{3}$ & NW & FET & $\begin{array}{l}254 \mathrm{~nm} \\
365 \mathrm{~nm} \\
\end{array}$ & 0.3 & - & $\begin{array}{c}290 \mathrm{nA}(254 \mathrm{~nm}) \\
33 \mathrm{nA}(365 \mathrm{~nm})\end{array}$ & - & $10 \mathrm{~s}$ & - & [57] \\
\hline $\mathrm{CeO}_{2}$ & NW film & Resistor & $254 \mathrm{~nm} ; 7 \mathrm{~W}$ & 5 & $\begin{array}{c}22.8 \mathrm{nA} \text { (air) } \\
0.35 \mathrm{pA}\left(\mathrm{H}_{2} \mathrm{O}\right)\end{array}$ & $\begin{array}{c}0.25 \mathrm{nA} \text { (air) } \\
0.44 \mathrm{nA}\left(\mathrm{H}_{2} \mathrm{O}\right)\end{array}$ & $\sim 1000$ & $\begin{array}{c}300 \mathrm{~s}(\text { air } \\
) \\
2 \mathrm{~s}\left(\mathrm{H}_{2} \mathrm{O}\right)\end{array}$ & 一 & [61] \\
\hline$\alpha-\mathrm{Fe}_{2} \mathrm{O}_{3}$ & NB & Resistor & $\begin{array}{l}400-800 \mathrm{~nm} ; \\
0.5 \mathrm{~mW} / \mathrm{cm}^{2}\end{array}$ & 0.8 & $10 \mathrm{nA}$ & $123 \mathrm{nA}(490 \mathrm{~nm})$ & $11-12$ & $20 \mathrm{~ms}$ & - & [56] \\
\hline$\alpha-\mathrm{MoO}_{3}$ & NB & Resistor & $\begin{array}{c}400-700 \mathrm{~nm} ; \\
10 \mathrm{~W}\end{array}$ & 0.1 & - & $0.22 \mu \mathrm{A}$ & - & - & - & [69] \\
\hline $\mathrm{MnO}_{2}$ & Nanosheet film & Resistor & $450 \mathrm{~nm}$ & - & - & - & - & - & - & [70] \\
\hline $\mathrm{ZnSnO}_{3}$ & NW & Resistor & $\begin{array}{l}\text { UV light; } \\
\text { Green laser }\end{array}$ & - & $0.3 \mathrm{nA}$ & $\begin{array}{l}162 \mathrm{nA}(\mathrm{UV}) \\
6.6 \mathrm{nA} \text { (green) }\end{array}$ & - & $20 \mathrm{~s}$ & - & [63] \\
\hline $\mathrm{ZnGa}_{2} \mathrm{O}_{4}$ & NW & Resistor & UV light & 30 & 8.5 PA & $1 \mathrm{nA}$ & - & - & - & [64] \\
\hline $\mathrm{RuO}_{2} / \mathrm{TiO}_{2}$ & Core/Shell NW & Resistor & $256 \mathrm{~nm}$ & - & $18.5 \mu \mathrm{A}$ & $19.4 \mu \mathrm{A}$ & - & $307 \mathrm{~s}$ & $437 \mathrm{~s}$ & [65] \\
\hline
\end{tabular}

*NW-nanowire; NB-nanobelt; ND-nanoneedle; NS-nanosheet; FET-field-effect transistors 
2. Device fabrication: In the conventional "pick and place" method, 1D nanostructures fabricated by vapor synthesis process are first collected from substrates on which they were initially grown and then, dispersed randomly on an insulating substrate after being diluted in a solution. Sophisticated techniques such as photolithography, electron beam lithography or focused ion beam are required to make metallic contacts to the nanostructures. Out of question, this process is complicated, time-consuming and uneconomic, thus hampering the development of practical routes [21]. It still remains a grand challenge to construct a device via a simple and effective method. Furthermore, since the performance of devices critically depends on the quality of the Ohmic contacts between a nanostructure and the electrodes, the construction of reliable and stable contacts is an urgent task that deserves particular attention.

3. Sensitivity, selectivity and stability (3S): Next generation photodetectors will require significant improvements in sensitivity, selectivity and stability $(3 \mathrm{~S})$ in order to meet the future demands in variety of fields. Though some research groups have successfully detected light using 1D metal oxide nanostructures, the selectivity and stability are still quite low.

4. Multi-functional detectors: The evolution of photodetectors goes in parallel with the development of microelectronics in which the architecture of photodetector elements is influenced by design trends in planar electronics. One of the major goals is to design nanodetectors that could be easily integrated into modern electronic fabrication technologies [8]. A possible avenue to differentiate the 1D nanostructure response maybe surface coating with chemical selective membrane, surface medication by specific functional groups, or combing multi-light and/or multi-gas sensing modules coupled with signal processing functions, acting as an "electronic nose" to differentiate in a more complex environment (Figure 11).

Figure 11. A sketch of a nanowire-based multi-functional detector [8].

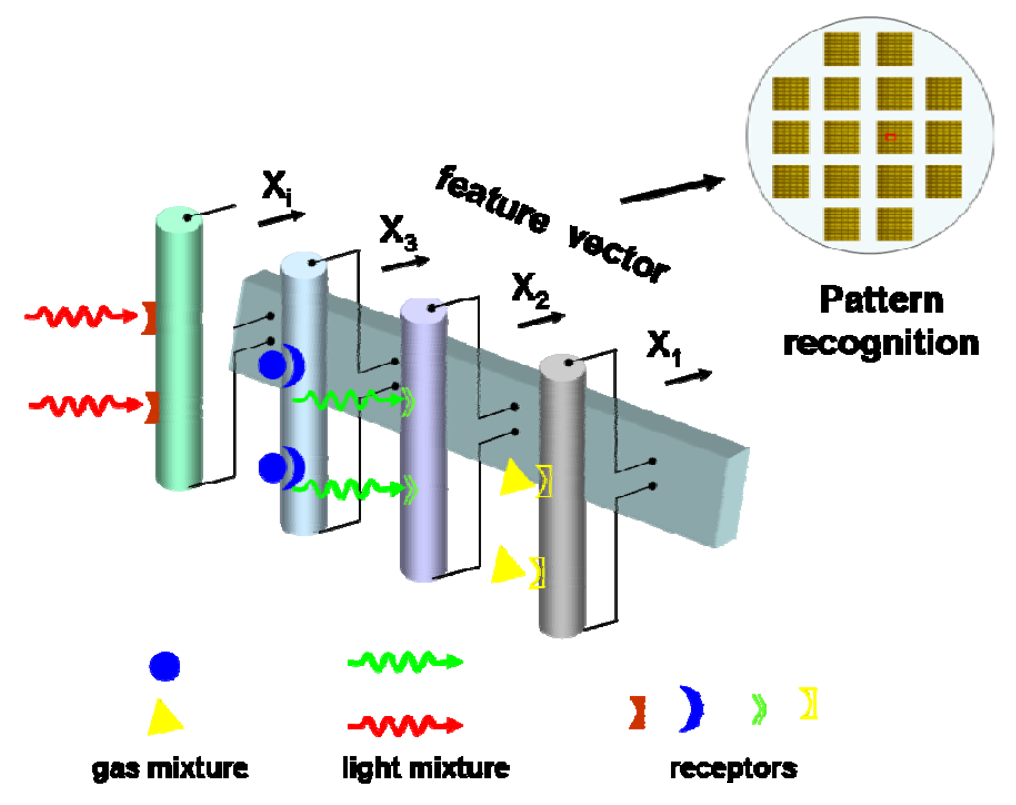

There is still plenty of room for the development of 1D metal-oxide nanostructures and their photodetector applications. We believe that future work in this direction should continue to focus on generating metal oxide nanostructures in a more controlled, predictable, reliable and simple way, and 
enhancing their photoconductor properties up to the level desirable in real industrial applications. The hopes are high that significant practical photodetector devices will soon arise due to the integration of 1D metal oxide nanostructures into conventional microelectronics.

\section{Acknowledgements}

This work was supported by the Japan Society for Promotion of Science (JSPS) in the form of a fellowship tenable at the National Institute for Materials Science (NIMS), Tsukuba, Japan (T. Y. Zhai). This work was also in part supported by the World Premier International Center for Materials Nanoarchitectonics (MANA) of the National Institute for Materials Science (NIMS), MEXT, Japan. The authors are indebted to Profs. D. Wang, P.D. Yang, C.W. Zhou, T. Yu, Y. Y. Li, T.H. Wang, A. Kolmakov, and M. Moskovits for their cooperation, kind help and offering some useful materials for the preparation of this review.

\section{References and Notes}

1. Yang, P.D.; Yan, H.Q.; Mao, S.; Russo, R.; Johnson, J.; Saykally, R.; Morris, N.; Pham, J.; He, R.; Choi, H.J. Controlled growth of $\mathrm{ZnO}$ nanowires and their optical properties. Adv. Mater. 2002, 12, 323-331.

2. Zhai, T.Y.; Zhong, H.Z.; Gu, Z.J.; Peng, A.D.; Fu, H.B.; Ma, Y.; Li, Y.F.; Yao, J.N. Manipulation of the morphology of $\mathrm{ZnSe}$ sub-micro structures using CdSe nanocrystals as the seeds. J. Phys. Chem. C 2007, 111, 2980-2986.

3. Lieber, C.M.; Wang, Z.L. Functional nanowires. MRS Bull. 2007, 32, 99-104.

4. Fang, X.S.; Bando, Y.; Gautam, U.K.; Ye, C.H.; Golberg, D. Inorganic semiconductor nanostructures and their field-emission applications. J. Mater. Chem. 2008, 18, 509-522.

5. Xia, Y.N.; Yang, P.D.; Sun, Y.G.; Wu, Y.Y.; Mayers, B.; Gates, B.; Yin, Y.D.; Kim, F.; Yan, H.Q. One-dimensional nanostructures: synthesis, characterization and applications. Adv. Mater. 2003, $15,353-389$.

6. Shen, G.Z.; Chen, P.C.; Ryu, K.; Zhou, C.W. Devices and chemical sensing applications of metal oxide nanowires. J. Mater. Chem. 2009, 19, 828-839.

7. Lu, J.G.; Chang, P.C.; Fan, Z.Y. Quai-one-dimensional metal oxide materials-synthesis, properties and applications. Mater. Sci. Eng. R 2006, 52, 49-91.

8. Kolmakov, A.; Moskovits, M. Chemical sensing and catalysis by one-dimensional metal-oxide nanostructures. Annu. Rev. Mater. Res. 2004, 34, 151-180.

9. Soci, C.; Zhang, A.; Xiang, B.; Dayeh, S.A.; Aplin, D.P.R.; Park, J.; Bao, X.Y.; Lo, Y.H.; Wang, D. $\mathrm{ZnO}$ nanowire UV photodetectors with high internal gain. Nano Lett. 2007, 7, 1003-1009.

10. Jiang, Y.; Zhang, W.J.; Jie, J.S.; Meng, X.M.; Fan, X.; Lee, S.T. Photoresponse properties of CdSe single-nanoribbon photodetectors. Adv. Funct. Mater. 2007, 17, 1795-1800.

11. Liao, M.Y.; Koide, Y.; Alvarez, J.; Imura, M.; Kleider, J.P. Persistent positive and transient absolute negative photoconductivity observed in diamond photodetectors. Phys. Rev. B 2008, 78, 045112:1-045112:9.

12. Kind, H.; Yan, H.Q.; Messer, B.; Law, M.; Yang, P.D. Nanowire ultraviolet photodetectors and optical switches. Adv. Mater. 2002, 14, 158-160. 
13. He, J.H.; Chang, P.H.; Chen, C.Y.; Tsai, K.T. Electrical and optoelectronic characterization of a $\mathrm{ZnO}$ nanowire contacted by focused-ion-beam-deposited Pt. Nanotechnology 2009, 20, 135701:1-135701:5.

14. Prades, J.D.; Hernandez-Ramirez, F.; Jimenez-Diaz, R.; Manzanares, M.; Andreu, T.; Cirera, A.; Romano-Rodriguez, A.; Morante, J.R. The effects of electron-hole separation on the photoconductivity of individual metal oxide nanowires. Nanotechnology 2008, 19, 465501:1-465501:7.

15. Comini, E.; Baratto, G.; Faglia, G.; Ferroni, M.; Vomiero, A.; Sberveglieri, G. Quasi-one dimensional metal oxide semiconductors: preparation, characterization and application as chemical sensors. Prog. Mater. Sci. 2009, 54, 1-67.

16. Wang, Z.L. Splendid one-dimensional nanostructures of zinc oxide: a new nanomaterial family for nanotechnology. ACS Nano 2008, 2, 1987-1992.

17. Wang, Z.L. Functional oxide nanobelts: materials, properties and potential applications in nanosystems and biotechnology. Annu. Rev. Phys. Chem. 2004, 55, 159-196.

18. Prades, J.D.; Jimenez-Diaz, R.; Hernandez-Ramirez, F.; Fernandez-Romero, L.; Andreu, T.; Cirera, A.; Romano-Rodriguez, A.; Cornet, A.; Morante, J.R.; Barth, S.; Mathur, S. Towards a systematic understanding of photodetectors based on individual metal oxide nanowires. J. Phys. Chem. C 2008, 112, 14639-14644.

19. Kim, W.; Chu, K.S. ZnO nanowire field-effect transistor as a UV photodetector; optimization for maximum sensitivity. Phys. Status. Solidi. A 2009, 206, 179-182.

20. Lin, D.D.; Wu, H.; Pan, W. Photoswitches and memories assembled by electrospinning aluminumdoped zinc oxide single nanowires. Adv. Mater. 2007, 19, 3968-3972.

21. Li, Y.B.; Valle, F.D.; Simonnet, M.; Yamada, I.; Delaunay, J.J. High-performance UV detector made of ultra-long ZnO bridging nanowires. Nanotechnology 2009, 20, 045501:1-045501:5.

22. Cheng, J.P.; Zhang, Y.J.; Guo, R.Y. ZnO microtube ultraviolet detectors. J. Cryst. Growth 2008, $310,57-61$.

23. Fan, Z.Y.; Chang, P.C.; Lu, J.G.; Walter, E.C.; Penner, R.M.; Lin, C.H.; Lee, H.P. Photoluminescence and polarized photodetection of single $\mathrm{ZnO}$ nanowires. Appl. Phys. Lett. 2004, $85,6128-6130$.

24. Zhou, J.; Gu, Y.D.; Hu, Y.F.; Mai, W.J.; Yeh, P.H.; Bao, G.; Sood, A.K.; Polla, D.L.; Wang, Z.L. Gigantic enhancement in response and reset time of ZnO UV nanosensor by utilizing Schottky contact and surface functionalization. Appl. Phys. Lett. 2009, 94, 191103:1-191103:3.

25. Park, D.; Yong, K. Photoconductivity of vertically aligned $\mathrm{ZnO}$ nanoneedle array. J. Vac. Sci. Technol. B 2008, 26, 1933-1936.

26. Fan, Z.Y.; Dutta, D.; Chien, C.J.; Chen, H.Y.; Brown, E.C.; Chang, P.C.; Lu, J.G. Electrical and photoconductive properties of vertical $\mathrm{ZnO}$ nanowires in high density arrays. Appl. Phys. Lett. 2006, 89, 213110:1-213110:3.

27. Law, J.B.K.; Thong, J.T.L. Simple fabrication of a $\mathrm{ZnO}$ nanowire photodetector with a fast photoresponse time. Appl. Phys. Lett. 2006, 88, 133114:1-133114:3.

28. Peng, L.; Zhai, J.L.; Wang, D.J.; Wang, P.; Zhang, Y.; Pang, S.; Xie, T.F. Anomalous photoconductivity of cobalt-doped zinc oxide nanobelts in air. Chem. Phys. Lett. 2008, 456, 231-235. 
29. Harnack, O.; Pacholski, C.; Weller, H.; Yasuda, A.; Wessels, J.M. Rectifying behavior of electrically aligned ZnO nanorods. Nano Lett. 2003, 3, 1097-1101.

30. Keem, K.; Kim, H.; Kim, G.T.; Lee, J.S.; Min, B.; Cho, K.; Sung, M.Y.; Kim, S. Photocurrent in $\mathrm{ZnO}$ nanowires grown from Au electrodes. Appl. Phys. Lett. 2004, 84, 4376-4378.

31. Li, Q.H.; Wan, Q.; Liang, Y.X.; Wang, T.H. Electronic transport through individual $\mathrm{ZnO}$ nanowires. Appl. Phys. Lett. 2004, 84, 4556-4558.

32. He, J.H.; Lin, Y.H.; McConney, M.E.; Tsukruk, V.V.; Wang, Z.L.; Bao, G. Enhancing UV photoconductivity of $\mathrm{ZnO}$ nanobelt by polyacrylonitrile functionalization. J. Appl. Phys. 2007, 102, 084303:1-084303:4.

33. Heo, Y.W.; Kang, B.S.; Tien, L.C.; Norton, D.P.; Ren, F.; Laroche, J.R.; Pearton, S.J. UV photoresponse of single $\mathrm{ZnO}$ nanowires. Appl. Phys. A 2005, 80, 497-499.

34. Hsu, C.L.; Chang, S.J.; Lin, Y.R.; Li, P.C.; Lin, T.S.; Tsai, S.Y.; Lu, T.H.; Chen, I.C. Ultraviolet photodetectors with low temperature synthesized vertical $\mathrm{ZnO}$ nanowires. Chem. Phys. Lett. 2005, 416, 75-78.

35. Luo, L.; Zhang, Y.F.; Mao, S.S.; Lin, L.W. Fabrication and characterization of ZnO nanowires based UV photodiodes. Sens. Actuat. A 2006, 127, 201-206.

36. Ghosh, R.; Dutta, M.; Basak, D. Self-seeded growth and ultraviolet photoresponse properties of ZnO nanowire arrays. Appl. Phys. Lett. 2007, 91, 073108:1-073108:3.

37. Ahn, S.E.; Ji, H.J.; Kim, K.; Kim, G.T.; Bae, C.H.; Park, S.M.; Kim, Y.K.; Ha, J.S. Origin of the slow photoresponse in an individual sol-gel synthesized ZnO nanowire. Appl. Phys. Lett. 2007, 90, 153106:1-153106:3.

38. Kouklin, N. Cu-doped $\mathrm{ZnO}$ nanowires for efficient and multispectral photodetection applications. Adv. Mater. 2008, 20, 2190-2194.

39. Aga, R.S.; Jowhar, D.; Ueda, A.; Pan, Z.; Collins, W.E.; Mu, R.; Singer, K.D.; Shen, J. Enhanced photoresponse in $\mathrm{ZnO}$ nanowires decorated with CdTe quantum dot. Appl. Phys. Lett. 2007, 91, 232108:1-232108:3.

40. Ahn, S.E.; Lee, J.S.; Kim, H.; Kim, S.; Kang, B.H.; Kim, K.H.; Kim. G.T. Photoresponse of solgel-synthesized ZnO nanorods. Appl. Phys. Lett. 2004, 84, 5022-5024.

41. Park, J.Y.; Yun, Y.S.; Hong, Y.S.; Oh, H.; Kim, J.J.; Kim, S.S. Synthesis, electrical and photoresponse properties of vertically well-aligned and epitaxial $\mathrm{ZnO}$ nanorods on GaN-buffered sapphire substrates. Appl. Phys. Lett. 2005, 87, 123108:1-123108:3.

42. Gao, P.; Wang, Z.Z.; Liu, K.H.; Xu, Z.; Wang, W.L.; Bai, X.D.; Wang, E.G. Photoconducting response on bending of individual $\mathrm{ZnO}$ nanowires. J. Mater. Chem. 2009, 19, 1002-1005.

43. Arnold, M.S.; Avouris, P.; Pan, Z.W.; Wang, Z.L. Field-effect transistors based on single semiconducting oxide nanobelts. J. Phys. Chem. B 2003, 107, 659-663.

44. Lin, C.C.; Lin, W.H.; Li, Y.Y. Synthesis of $\mathrm{ZnO}$ nanowires and their applications as an ultraviolet photodetector. J. Nanosci. Nanotechnol. 2009, 9, 2813-2819.

45. Hsu, C.L.; Hsueh, T.J.; Chang, S.P. Preparation of $\mathrm{ZnO}$ nanoflakes and a nanowire-based photodetector by localized oxidation at low temperature. J. Electrochem. Soc. 2008, 155, K59-K62. 
46. Liu, Z.Q.; Zhang, D.H.; Han, S.; Li, C.; Tang, T.; Jin, W.; Liu, X.L.; Lei, B.; Zhou, C.W. Laser ablation synthesis and electron transport studies of Tin Oxide nanowires. Adv. Mater. 2003, 15, 1754-1757.

47. Mathur, S.; Barth, S.; Shen, H.; Pyun, J.C.; Werner, U. Size-dependent photoconductance in $\mathrm{SnO}_{2}$ nanowires. Small 2005, 1, 713-717.

48. Liao, L.; Yan, B.; Hao, Y.F.; Xing, G.Z.; Liu, J.P.; Zhao, B.C.; Shen, Z.X.; Wu, T.; Wang, L.; Thong, J.T.L.; Li, C.M.; Huang, W.; Yu, T. P-type electrical, photoconductive, and anomalous ferromagnetic properties of $\mathrm{Cu}_{2} \mathrm{O}$ nanowires. Appl. Phys. Lett. 2009, 94, 113106:1-113106:3.

49. Yang, Z.; Chiang, C.K.; Chang, H.T. Synthesis of fluorescent and photovoltaic $\mathrm{Cu}_{2} \mathrm{O}$ nanocubes. Nanotechnology 2008, 19, 025604:1-025604:7.

50. Singh, D.P.; Neti, N.R.; Sinha, A.S.K.; Srivastava, O.N. Growth of different nanostructures of $\mathrm{Cu}_{2} \mathrm{O}$ (nanothreads, nanowires, and nanocubes) by simple electrolysis based oxidation of copper. J. Phys. Chem. C 2007, 111, 1638-1645.

51. Feng, P.; Zhang, J.Y.; Li, Q.H.; Wang, T.H. Individual $\beta-\mathrm{Ga}_{2} \mathrm{O}_{3}$ nanowires as solar-blind photodetectors. Appl. Phys. Lett. 2006, 88, 153107:1-153107:3.

52. Hu, J.Q.; Li, Q.; Zhan, J.H.; Jiao, Y.; Liu, Z.W.; Ringer, S.P.; Bando, Y.; Golberg, D. Unconventional ribbon-shaped $\beta-\mathrm{Ga}_{2} \mathrm{O}_{3}$ tubes with mobile $\mathrm{Sn}$ nanowire fillings. ACS Nano $\mathbf{2 0 0 8}$, 2, 107-112.

53. Feng, P.; Xue, X.Y.; Liu, Y.G.; Wan, Q.; Wang, T.H. Achieving fast oxygen response in individual $\beta-\mathrm{Ga}_{2} \mathrm{O}_{3}$ nanowires by ultraviolet illumination. Appl. Phys. Lett. 2006, 89, 112114:1-112114:3.

54. Eranna, G.; Joshi, B.C.; Runthala, D.P.; Gupta, R.P. Oxide materials for development of integrated gas sensors-a comprehensive review. Crit. Rev. Solid State Mat. Sci. 2004, 29, 111-188.

55. Huang Y.; Wang, Z.L.; Wang, Q.; Gu, C.Z.; Tang, C.C.; Bando, Y.; Golberg, D. Quasi-aligned $\mathrm{Ga}_{2} \mathrm{O}_{3}$ nanowires grown on brass wire meshes and their electrical and field-emission properties. $J$. Phys. Chem. C 2009, 113, 1980-1983.

56. Hsu, L.C.; Kuo, Y.P.; Li, Y.Y. On-chip fabrication of an individual $\alpha-\mathrm{Fe}_{2} \mathrm{O}_{3}$ nanobridge and application of ultrawide wavelength visible-infrared photodetector/optical switching. Appl. Phys. Lett. 2009, 94, 133108:1-133108:3.

57. Zhang, D.; Li, C.; Han, S.; Liu, X.; Tang, T.; Jin, W.; Zhou, C. Ultraviolet photodetection properties of indium oxide nanowires. Appl. Phys. A 2003, 77, 163-166.

58. Zhang, D.H.; Li, C., Han, S.; Liu, X.L.; Tang, T.; Jin, W.; Zhou, C.W. Electronic transport studies of single-crystalline $\mathrm{In}_{2} \mathrm{O}_{3}$ nanowires. Appl. Phys. Lett. 2003, 82, 112-114.

59. Li, C.; Zhang, D.H.; Han, S.; Liu, X.L.; Tang, T.; Zhou, C.W. Diameter-controlled grown of single-crystalline $\mathrm{In}_{2} \mathrm{O}_{3}$ nanowires and their electronic properties. Adv. Mater. 2003, 15, 143-146.

60. Liu, X.L.; Li, C.; Han, S.; Han, J.; Zhou, C.W. Synthesis and electronic transport studies of CdO nanoneedles. Appl. Phys. Lett. 2003, 82, 1950-1952.

61. Fu, X.Q.; Wang, C.; Feng, P.; Wang, T.H. Anomalous photoconductivity of $\mathrm{CeO}_{2}$ nanowire in air. Appl. Phys. Lett. 2007, 91, 073104:1-073104:3.

62. Liao, L.; Mai, H.X.; Yuan, Q.; Lu, H.B.; Li, J.C.; Liu, C.; Yan, C.H.; Shen, Z.X.; Yu, T. Single $\mathrm{CeO}_{2}$ nanowire gas sensor supported with Pt nanocrystals: gas sensitivity, surface bond states, and chemical mechanism. J. Phys. Chem. C 2008, 112, 9061-9065. 
63. Xue, X.Y.; Guo, T.L.; Lin, Z.X. Wang, T.H. Individual core-shell structured $\mathrm{ZnSnO}_{3}$ nanowires as photoconductors. Mater. Lett. 2008, 62, 1356-1358.

64. Feng, P.; Zhang, J.Y.; Wan, Q.; Wang, T.H. Photocurrent characteristics of individual $\mathrm{ZnGa}_{2} \mathrm{O}_{4}$ nanowires. J. Appl. Phys. 2007, 102, 074309:1-074309:5.

65. Chueh, Y.L.; Hsieh, C.H.; Chang, M.T.; Chou, L.J.; Lao, C.S.; Song, J.H.; Gan, J.Y.; Wang, Z.L. $\mathrm{RuO}_{2}$ nanowires and $\mathrm{RuO}_{2} / \mathrm{TiO}_{2}$ core/shell nanowires: from synthesis to mechanical, optical, electrical, and photoconductive properties. Adv. Mater. 2007, 19, 143-149.

66. Chen, Y.J.; Zhu, C.L.; Cao, M.S.; Wang, T.H. Photoresponse of $\mathrm{SnO}_{2}$ nanobelts grown in situ on interdigital electrodes. Nanotechnology 2007, 18, 285502:1-285502:5.

67. Lin, C.H.; Chen, R.S.; Chen, T.T.; Chen, H.Y.; Chen, Y.F.; Chen, K.H.; Chen, L.C. High photocurrent gain in $\mathrm{SnO}_{2}$ nanowires. Appl. Phys. Lett. 2008, 93, 112115:1-112115:3.

68. Kuang, Q.; Lao, C.S.; Li, Z.; Liu, Y.Z.; Xie, Z.X.; Zheng, L.S.; Wang, Z.L. Enhancing the photoand gas-sensing properties of a single $\mathrm{SnO}_{2}$ nanowire based nanodevice by nanoparticle surface functionalization. J. Phys. Chem. C 2008, 112, 11539-11544.

69. Cheng, L.; Shao, M.W.; Wang, X.H.; Hu, H.B. Single-crystalline Molybdnum Trioxide nanoribbons: photocatalytic, photoconductive, and electrochemical properties. Chem. Eur. J. 2009, $15,2310-2316$.

70. Sakai, N.; Ebina, Y.; Takada, K.; Sasaki, T. Photocurrent generation from semiconducting Manganese Oxide nanosheets in response to visible light. J. Phys. Chem. B 2005, 109, 9651-9655.

(C) 2009 by the authors; licensee Molecular Diversity Preservation International, Basel, Switzerland. This article is an open-access article distributed under the terms and conditions of the Creative Commons Attribution license (http://creativecommons.org/licenses/by/3.0/). 